\title{
Simulations of Cortical Pyramidal Neurons Synchronized by Inhibitory Interneurons
}

\author{
WILLIAM W. LYTTON AND TERRENCE J. SEJNOWSKI \\ The Salk Institute, Computational Neurobiology Laboratory, La Jolla 92037; and Department of Biology, \\ University of California, San Diego, La Jolla, California 92093
}

\section{SUMMARY AND CONCLUSIONS}

1. The interaction between inhibitory interneurons and cortical pyramidal neurons was studied by use of computer simulations to test whether inhibitory interneurons could assist in phaselocking postsynaptic cells. Two models were used: a simplified model, which included only 3 membrane channels, and a detailed 11-channel model.

2. The 11-channel model included most of the ion channels known to be present in neocortical pyramidal neurons as well as calcium diffusion and other membrane mechanisms. The kinetics for the channels were obtained from voltage-clamp studies in a variety of preparations. The parameters were then adjusted to produce repetitive bursting similar to that seen in some cortical pyramidal cells entrained during visual stimulation.

3. Phase-locking to a train of inhibitory postsynaptic potentials (IPSPs) located on or near the soma was observed in the 3-channel model cell subjected to random synaptic bombardment. In the 11-channel model, phase-locking due to multiple IPSPs was compared with phase-locking due to multiple excitatory postsynaptic potentials (EPSPs). Phase-locking began to occur when $20 \%$ of the IPSPs $(20 / 100)$ or $40 \%$ of the EPSPs $(4,000 / 10,000)$ were synchronized. The exact percentages differed with different 11-channel models, but either EPSPs or IPSPs would generally produce entrainment with $\sim 40 \%$ synchronization. Thus 40 inhibitory boutons had an effect equivalent to 4,000 excitatory boutons in producing phase-locking.

4. Phase-locking with IPSPs in these models was possible because the IPSPs could cause either an increase or a decrease in firing rate over a limited range. The IPSPs served a modulatory role, increasing the rate of firing in some cases and decreasing it in others, depending on the state of the cell.

5. We examined frequency entrainment by IPSPs. In the 3channel model, frequency entrainment of a postsynaptic cell was observed with a rapid train of strong (20-100 nS), brief, compound IPSPs. A $40-\mathrm{Hz}$ compound IPSP train of $60 \mathrm{nS}$ entrained cells having initial firing rates between 32 and $47 \mathrm{~Hz}$. Below this range, cells could be partially entrained. Above the range, entrainment would fail. Frequency entrainment in the 3-channel model generally occurred on the first cycle after onset of the IPSPs.

6. Phase-locking and frequency entrainment were less robust in the 11-channel model. This was partly because bursts rather than individual spikes were being entrained. A 40-Hz, 90-nS compound IPSP train entrained a model cell upward from $34 \mathrm{~Hz}$. Downward frequency entrainment also occurred. In the 11-channel model entrainment usually occurred on the second cycle after onset of the IPSPs.

7. Downward frequency entrainment was due to the direct effects of inhibition in delaying firing of the cell.The occurrence of upward frequency entrainment was more surprising and was studied in detail. The upward entrainment observed in the 3-channel model occurred because hyperpolarization turned off a slow potassium channel, making subsequent firing more likely. Acceleration from low to higher frequency also occurred in the 11-channel model, but was due to a different mechanism. The IPSPs reduced the burst size and allowed less calcium to enter the cell, which reduced the interburst hyperpolarization mediated by a $\mathrm{Ca}^{2+}$-sensitive $\mathrm{K}^{+}$current. The occurrence of IPSP frequency entrainment by distinctly different mechanisms in these different models suggests that the phenomenon might occur in a variety of cells.

8. The large conductances needed to obtain phase-locking in our simulations could be produced by the coordinated firing of six to eight inhibitory basket cells making multiple synaptic contacts onto somas or proximal apical dendrites of pyramidal neurons. In both models, IPSP phase-locking was shown to be effective with the use of shunting inhibition with the IPSP located on the proximal dendrite. Therefore $\gamma$-aminobutyric acid-A synapses could be involved. In the 3-channel model we also showed phase-locking by the use of synapses onto the axon initial segment. This suggests that chandelier cells could also play a role in phase-locking.

9. IPSP entrainment could contribute to the phase-locking observed in visual cortex. Support for this comes from previous reports of brief, rapid IPSP trains at optimal stimulation of orientation-tuned cells in visual cortex.

\section{INTRODUCTION}

The appearance of large population potentials in cerebral cortex, thalamus, and hippocampus suggests extensive correlated neuronal discharge. Recent studies have shown that synchronized firing of neurons in visual cortex occurs in response to visual stimulation (Eckhorn et al. 1988; Gray et al. 1989). Many mechanisms could explain these phaselocked responses, including excitatory pacemakers and excitatory feedback loops from other cortical regions (Bush and Douglas 1991; Eckhorn et al. 1990; Kammen et al. 1990; Konig and Schillen 1991a,b). We propose that certain classes of inhibitory interneurons could play a role in the maintenance of cortical phase-locking. We performed computer simulations to find conditions under which this hypothesis could be valid.

Inhibitory interneurons have generally been assumed to invariably reduce activity levels in postsynaptic neurons (Collonier 1981). However, the small conductance change associated with measured inhibitory postsynaptic potentials (IPSPs) suggests that in many cases they may not be powerful enough to reduce firing appreciably (Douglas and Martin 1990a). Postsynaptic potentials (PSPs) are classified as excitatory (EPSPs) or inhibitory according to their reversal potential relative to threshold, but recent modeling studies have shown that IPSPs can be facilitatory and EPSPs can be defacilitatory (Davenport et al. 1989; Lytton 1991; 
Moore et al. 1989). These paradoxical effects have also been demonstrated physiologically in cerebellar nuclei (Llinás and Mühlethaler 1988) and in invertebrates (Bryant et al. 1973). With the proper timing, an IPSP can increase the probability of firing in response to a subsequent EPSP and might be better described as a facilitating IPSP. In these studies, the facilitation is due to deinactivation of inward sodium and calcium conductances, with concomitant decrease of outward potassium conductances at the hyperpolarized membrane potential. The IPSP is facilitatory because it decreases the cell's threshold to firing after the hyperpolarization has passed. The membrane "memory" that permits this is due to the time constant of the voltage-sensitive channels. This is closely related to the phenomenon of anode break, in which firing occurs after release of a cell from a hyperpolarizing current-clamp. As we shall show, such paradoxical effects can be caused by other mechanisms as well.

We examined two different models. The first model, which we call the 3 -channel model, contained only three voltage-sensitive channels and served as a simplified model neuron. This is a model of a regularly firing cell that produces firing at a single frequency in response to a constant current injection. Observations in visual cortex have shown that bursts of action potentials rather than single spikes are entrained, suggesting that these cells may be repetitive bursters (Gray et al. 1991). Therefore the second model, which contained 11 channels, was designed to produce repetitive bursting in response to current-clamp. This model included many of the channels and membrane mechanisms observed in cortical pyramidal neurons.

The 3-channel model used far less computer time and could be explored more extensively. The mechanism of frequency entrainment in the 3-channel model could be clearly explicated by phase plane analysis. The 11-channel model was used to confirm that the basic phenomenon was also present with the multiple cellular mechanisms present in a cortical pyramidal cell. Such detailed modeling is lim- ited by difficulties in interpreting voltage-clamp data, in manipulating a large number of parameters, and in calculating many parallel differential equations. Despite these difficulties, we were able to use this model to explore interactions between synaptic inputs and intrinsic cell properties that may underlie the synchronized activity observed in cortical neurons.

\section{METHODS}

Simulations were performed on MIPS M/120 and MIPS Magnum 3000 computers with a modified version of the neuronal simulation program CABLE developed by $\mathrm{M}$. Hines and $\mathrm{J}$. Moore (Hines 1989). This simulator uses Crank-Nicholson integration with Gaussian elimination of the resulting tridiagonal matrix as well as table look up for the integration of Hodgkin-Huxley state variables. This allowed us to simulate $1 \mathrm{~s}$ of a 406-compartment model with a full complement of 11 channels, calcium diffusion, and 600 synapses, using a $1-\mu$ s time step, in $8.25 \mathrm{~h}$. The small time step of $1 \mu \mathrm{s}$ was required to ensure convergence for all initial conditions, although many simulations were accurate with much larger time steps. Convergence was confirmed with a run using a time step of $250 \mathrm{~ns}$. Because of the large amount of computer time required to simulate the more complex model, we were not able to explore the parameter space for this model as thoroughly as that of the 3-channel model. Most simulations of the 3-channel model were done with a time step of $25 \mu \mathrm{s}$. This allowed us to simulate $1 \mathrm{~s}$ in $\sim 10 \mathrm{~min}$. Shorter time steps were used to verify convergence of the integration. Overall, $\sim 3,000$ simulations were run, 1,500 with the 3-channel model and 1,500 with the 11-channel model. About $75 \%$ of these 11-channel model simulations were done during the course of setting the parameters. These exploratory simulations resulted in three different parameter combinations for the 11channel model, which were used to explore phase-locking. The three parameter combinations arose as improvements were made on the model. Therefore we only provide the parameters from our final model. About 100 simulations were run with the two preliminary parameter sets and $\sim 200$ simulations with the final set.

\section{Morphology}

The 3-channel model used nine cylindrical compartments (Fig. $1 A$ ). The cell body had a diameter of $10 \mu \mathrm{m}$ and a length of $22 \mu \mathrm{m}$.
$\mathbf{A}$

B
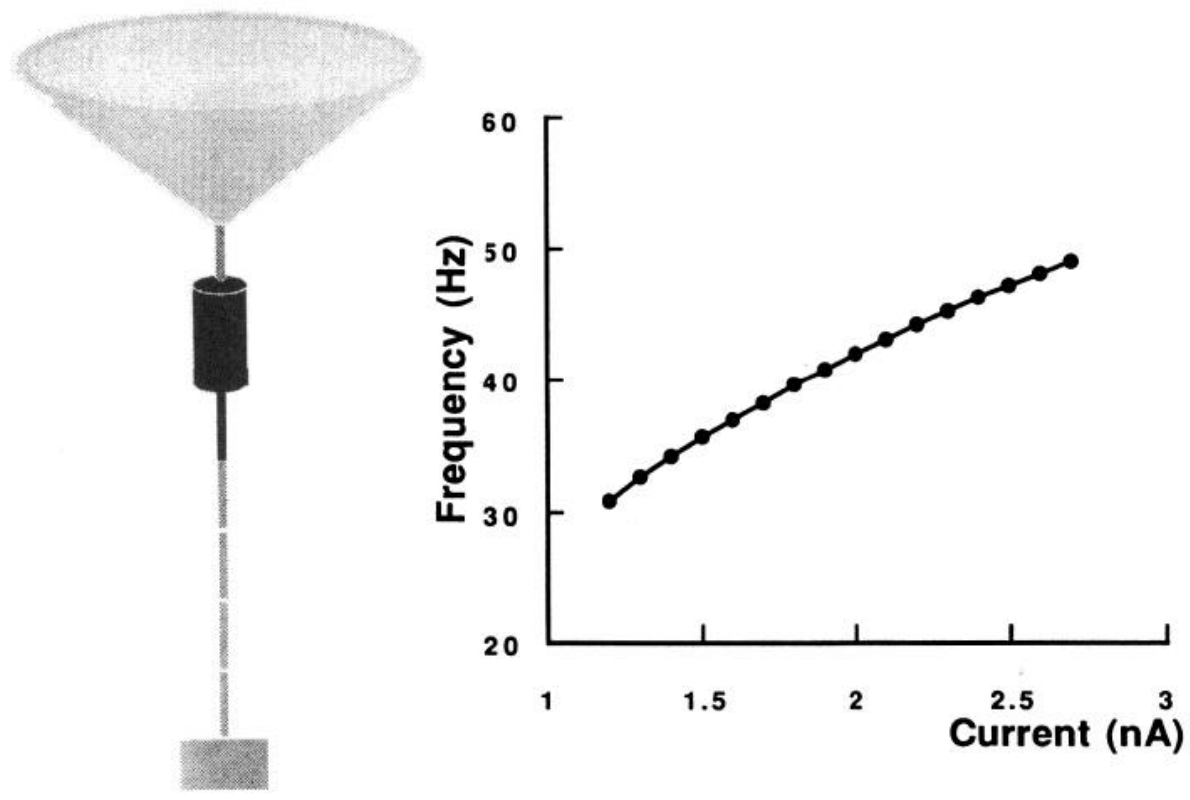

FIG. 1. Three-channel model. $A$ : schematic diagram of 3-channel model illustrates dendritic tree, represented by a single large compartment (here drawn as a cone), connected to soma by proximal dendrite. Axon is similarly terminated by a large low-impedance compartment bottom. Active channels were restricted to the axon initial segment (black) and the soma (large black cylinder). $B$ : firing frequency of 3-channel model with different levels of current-clamp. Model shows regular firing with no adaptation. 
The apical dendritic load was reproduced using a long, thin (1 $\times 35 \mu \mathrm{m}$ ) proximal compartment leading to a low-impedance $(350 \times 35 \mu \mathrm{m})$ compartment. The axon was represented as a series of six compartments $(0.9 \times 50 \mu \mathrm{m})$ terminated with a low-impedance compartment. The most proximal of these compartments was considered the axon initial segment.

For the 11-channel model, the morphology of a cortical pyrami-
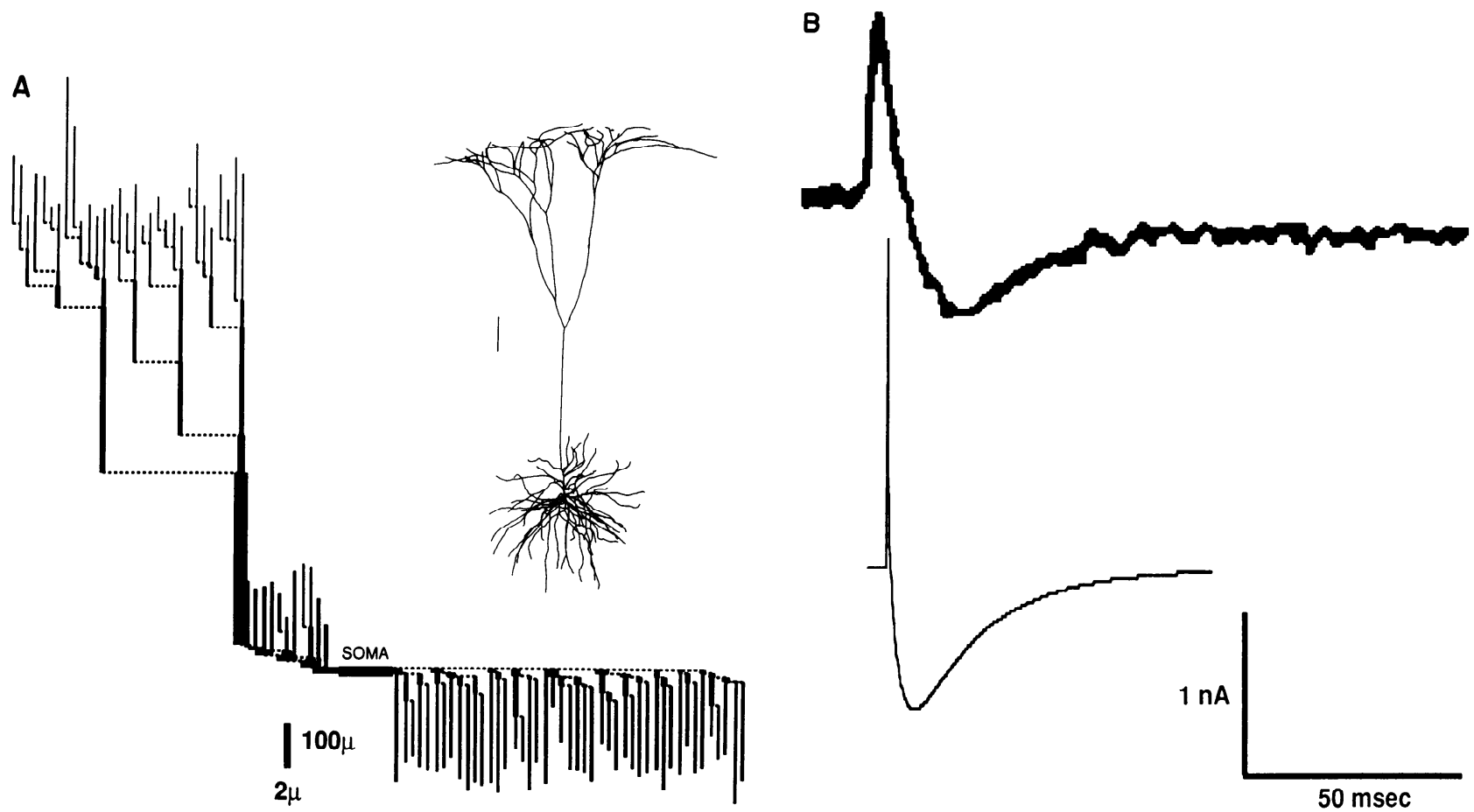

C

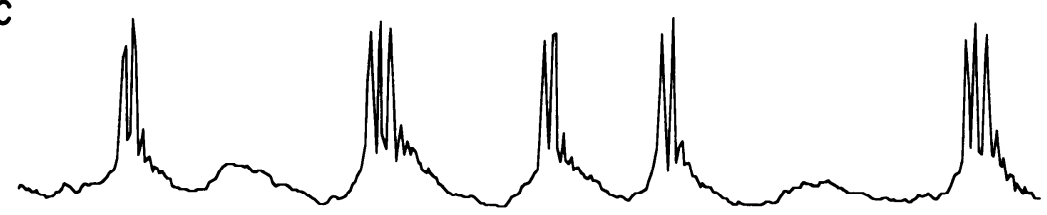

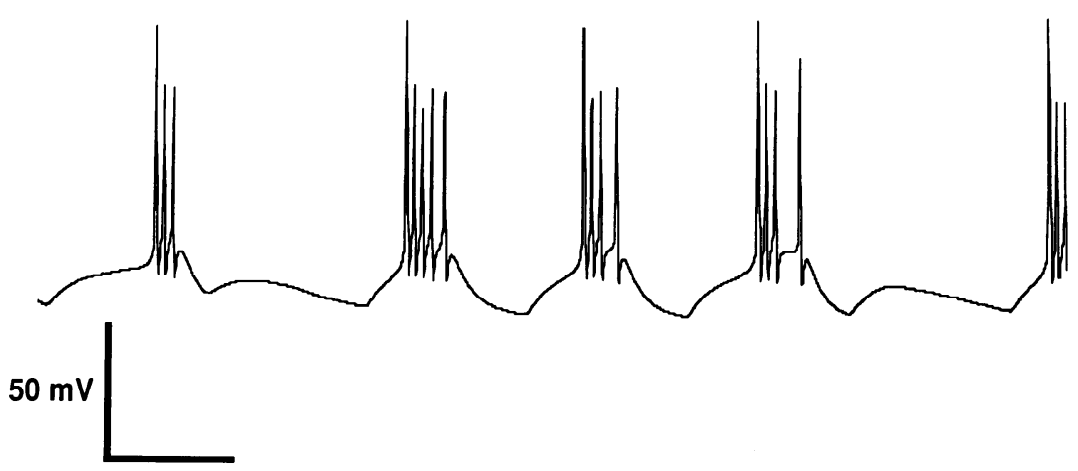

$25 \mathrm{msec}$

FIG. 2. Eleven-channel model. $A$ : scale diagram of the 11-channel compartment model. Morphology of this cell (inset) is identical to that shown in Fig. $3 A$ in Koch et al. (1990) and in Fig. $1 A$ in Bush and Douglas (1991). The 407 individual compartments used in the model cannot all be distinguished in this diagram. Apical dendrite is represented to the left of the soma and the basilar dendrites are represented to the right. Lengths and widths of compartments are given by lengths and widths of vertical lines. Horizontal dotted lines show where dendrites are connected but do not represent compartments themselves. Axon is not shown in this diagram. $B$ : voltage-clamp trace of a pyramidal neuron from a rat frontal cortex slice in response to 35-mV depolarizing step in the presence of TEA and cesium to block potassium channels (Fig. $6 \mathrm{~A}$ in Sutor and Zieglgänsberger 1987) (top) compared with simulated voltage clamp of isolated calcium current ( $L, N$, and $T$ combined) $($ bottom) in response to same-size current step. $C$ : intracellular recording from pyramidal cell of neocortex (Fig. $3 C$ in Bush and Douglas 1991) (top) compared with membrane potential from soma of simulated neuron receiving multiple synaptic inputs (bottom). A sample that fortuitously resembled the data was selected from the series of simulations illustrated in Fig. 11 with $100 \%$ EPSP, 0\% IPSP synchronization. 
to $0.9 \mu \mathrm{m}$. In both models resting membrane potential was taken to be $-65 \mathrm{mV}$ (Connors et al. 1982), membrane capacitance was 1 $\mu \mathrm{F} / \mathrm{cm}^{2}$, and longitudinal resistance was $100 \Omega-\mathrm{cm}$.

\section{Synapses}

Both excitatory and inhibitory synaptic conductances were modeled by an $\alpha$ function (Jack et al. 1983) with a time to peak of $1 \mathrm{~ms}$. The resulting IPSP had a half-peak duration of $\sim 5 \mathrm{~ms}$ because of the filtering effect of passive membrane properties on voltage. PSP duration appears to be largely due to the time constant of the postsynaptic cell (Mason et al. 1991). The duration we used was slightly shorter than IPSPs observed in guinea pig neocortical slices (Fig. 3 in Galvan et al. 1985; Fig. 6 in Prince and Huguenard 1988) and in human cortex (McCormick 1989).

In the 3-channel model, the primary inhibitory synapses were placed on the proximal apical dendrite, the soma, or the axon initial segment. Maximal IPSP conductances from 20 to $100 \mathrm{nS}$ were used. Both shunting and hyperpolarizing inhibition were assessed. In the 11-channel model, inhibitory synapses were located exclusively on the proximal apical dendrite. A maximal IPSP conductance of $90 \mathrm{nS}$ was used, corresponding to the value measured by changes in input impedance in layer II/III of cat visual cortex slices in response to cathode stimulation of underlying white matter (Connors et al. 1988). This was assumed to be a chloride-mediated $\alpha$-aminobutyric acid-A $\left(\mathrm{GABA}_{\mathrm{A}}\right)$ conductance with a reversal potential of $-75 \mathrm{mV}, 10 \mathrm{mV}$ below resting membrane potential (Thompson et al. 1988).

In the 11-channel model, 600 synapses were explicitly represented to assess the effect of multiple synaptic input. Of these, 500 were individual excitatory synapses that had a conductance of 10 $\mathrm{nS}$ and a reversal potential of $0 \mathrm{mV}$. The time of firing for each individual EPSP was random, occurring according to a Poisson process with a mean frequency of $37 \mathrm{~Hz}$. The number and strength of the excitatory synapses was chosen so as to drive the cell at the desired bursting frequency of $30-40 \mathrm{~Hz}$. A neocortical pyramidal cell may have up to 10,000 synaptic boutons (Douglas and Martin $1990 \mathrm{~b}$ ). Our total synaptic conductance is roughly equivalent to 10,000 excitatory boutons, each with a maximal conductance of $0.5 \mathrm{nS}$. A total inhibitory conductance of $100 \mathrm{nS}$ was divided into 100 individual inhibitory synapses, each with a $1 \mathrm{nS}$ conductance and the same $\mathrm{GABA}_{\mathrm{A}}$ reversal potential. These individual IPSPs were meant to represent input from individual boutons. The number of boutons approximates the total number of flat-vesicle con- taining synaptic specializations seen on the soma and proximal dendrite of cat layer IV pyramidal cells examined with electron microscopy (Davis and Sterling 1979). The EPSPs were placed in the distal dendritic field, and the IPSPs were placed proximally to correspond to the distribution of synapses onto cortical pyramidal cells. Inhibitory synapses in the dendrites above the proximal compartment were not included.

In the 3-channel model, the effect of multiple synaptic activation was produced by a random synaptic potential generator. A randomizer provided a conductance value between 0 and $100 \mathrm{nS}$ as well as a reversal potential between -90 and $-40 \mathrm{mV}$ on each time step. The high-frequency noise that resulted was low-pass filtered by placing it in the distal compartment. The parameters used in this approach do not correspond to particular synapses. The technique was developed to generate an irregular voltage baseline that was qualitatively similar to that in a cell model receiving 2,000 uncorrelated synaptic inputs.

\section{Modeling of voltage-gated ionic channels}

Hodgkin and Huxley's original study (1952) of the ionic conductances underlying the action potential remains the basic framework for modeling ionic conductances in many neuron models. Although we used many types of channels, each is defined within the framework of this original approach. All of the channels have an activation variable, and some have an inactivation variable as well. Following Hodgkin and Huxley's original choice of variables for the sodium channel, the activation variable is called $m$ and the inactivation variable is called $h$. (We use $m$ as a generic activation variable and $h$ as a generic inactivation variable for all channels in the 11-channel model. Other variable names are also used in the 3-channel model.) Each variable is defined in terms of its time derivative and evolves in time according to a steady-state value $\left(m_{\infty}\right.$ or $\left.h_{\infty}\right)$ and a time constant $\left(\tau_{m}\right.$ or $\left.\tau_{h}\right)$ (Hille 1984). Each of these is a function of voltage $(V)$ defined in terms of kinetic variables, $\alpha(V)$ and $\beta(V)$, given in units of inverse time. These give the voltage-dependent rate of channel state transitions in a Markov model from closed toward open $(\alpha)$ and from open toward closed $(\beta)$

$$
\begin{gathered}
m_{\infty}(V)=\frac{\alpha_{m}(V)}{\alpha_{m}(V)+\beta_{m}(V)} \quad \tau_{m}(V)=\frac{1}{\alpha_{m}(V)+\beta_{m}(V)} \\
h_{\infty}(V)=\frac{\alpha_{h}(V)}{\alpha_{h}(V)+\beta_{h}(V)} \quad \tau_{h}(V)=\frac{1}{\alpha_{h}(V)+\beta_{h}(V)}
\end{gathered}
$$

TABLE 1. Channel kinetics



$\bar{g}$, conductance; $\bar{p}$, permeability; $V$, voltage; $T$, temperature; $E$, potential; $I$, current. 
For the 3-channel model, we used channel definitions taken from other modeling studies. For the 11-channel model, however, we used voltage-clamp data to determine the parameters.

The 11-channel model included most of the channels that have been demonstrated in cortical pyramidal cells in mammals. Voltage-clamp studies from cortical pyramidal cells were used to determine the types of channels needed and the approximate maximal conductance for a particular channel type $(\bar{g})$. Better voltageclamp data were usually available from nonneocortical cells, and these studies were used to determine the precise kinetics for the channels. Most voltage-clamp studies directly provided the voltage dependence of activation and inactivation for a particular channel $\left(m_{\infty}\right.$ and $\left.h_{\infty}\right)$. Time constants could be estimated by measuring the time for reaching maximum current at various voltages $\left(\tau_{m}\right)$ and for returning to the closed state after being clamped at these voltages $\left(\tau_{h}\right)$. In many cases, a full set of voltage-clamp traces for all different voltages was not made available, so that time constants could be obtained for only selected voltages. In this case, it was necessary to have some means of interpolating between these points to obtain full $\tau_{m}(V)$ and $\tau_{h}(V)$ curves. This was possible because the Hodgkin-Huxley formulation relates the steady-state values $\left(m_{\infty}, h_{\infty}\right)$ to the time constants $\left(\tau_{m}, \tau_{h}\right)$ by way of the variables $\alpha$ and $\beta$ (Eq. l).

Originally, Hodgkin and Huxley defined formulas for only two types of channels. We employed Borg-Graham's generalization of their formulas (Borg-Graham 1987, 1991), which defined the $\alpha$ 's and $\beta$ 's as follows

$$
\alpha=\alpha_{0} e^{[z \gamma(V-V / / 2) \mathcal{P}] / R T} \quad \beta=\beta_{0} e^{\left[-z(1-\gamma)\left(V-V_{/ 2}\right) \mathcal{I}\right] / R T}
$$

where $\mathcal{F}$ is the Faraday constant, $R$ is the gas constant, and $T$ is temperature. The choice of parameters $\alpha_{0}, \beta_{0}, z, \gamma$, and $V_{1 / 2}$ determines the kinetics of the individual channels (see Table 1). One set of parameters defines both $\alpha(V)$ and $\beta(V)$ for a single activation or inactivation variable.

The Borg-Graham modification of the original Hodgkin-Huxley parameterization has several advantages. First, where Hodgkin-Huxley used slightly different functions for the several $\alpha$ 's and $\beta$ 's required, the Borg-Graham formalism provides a single definition that can be used for many different channels. Second, the equations are close to the Boltzmann function description of activation and inactivation used in many voltage-clamp studies

$$
m_{\infty}=\frac{I}{I_{\max }}=1 /\left(1+e^{\left(V-V^{\prime} / 2\right) / K}\right)
$$

where $K$ is an empirically fitted parameter ( $E q .3$ from Coulter et al. 1989a). This formula is identical in form to the $m_{\infty}$ obtained by using the $\alpha$ and $\beta$ of Eq. 2 in Eq. 1 for $m_{\infty}$. Therefore the value for $V_{1 / 2}$ given for the Boltzmann equation can be used directly in the Borg-Graham equations. The value for $z$ in the Borg-Graham equation can be obtained from $K$ by

$$
z=-\frac{R \cdot T}{\mathcal{F}} \cdot \frac{1}{K}
$$

Third, the form of the equations makes them easy to manipulate to fit data for activation and inactivation voltage and time dependence taken from a table or graph in voltage-clamp study of a particular channel. This is possible because each individual parameter has a specific effect on the shape of the $m_{\infty}$ (or $h_{\infty}$ ) and $\tau_{m}$ (or $\tau_{h}$ ) curve. The steepness of the curve is given by $z$, where larger $z$ gives a steeper curve. Additionally, the sign of $z$ determines whether the curve is increasing (for $m_{\infty}$ ) or decreasing (for $h_{\infty}$ ). $V_{1 / 2}$ gives the midpoint of the voltage-dependent curve in millivolts. Changing this parameter shifts the curve to the left or right. The magnitude of $\alpha_{0}$ and $\beta_{0}$ (generally set to be equal) is inversely proportional to the magnitude of the time constant, $\tau_{m}$ or $\tau_{h}$. The parameter $\gamma$, which takes values between 0 and 1 , skews $\tau(V)$ toward the right or left. Finally, an additional parameter, $\tau_{\min }$, is used to give a minimum value for $\tau$. A final advantage of the Borg-Graham formalism is that the individual parameters can be interpreted in terms of underlying channel biophysics (Borg-Graham 1991).

After establishing the kinetics for a particular conductance, it was necessary to determine the channel density for the conductance. In some cases, the density could be estimated from the maximal current detected during voltage-clamp. In other cases, the value obtained in this way had to be modified for one of two reasons. First, some channels have a voltage dependence of opening that causes them to have significant conductance at rest. In these cases, the channel's contribution to the resting potential must be compensated by other resting conductances associated with reversal potentials lying on the opposite side of the resting membrane potential. Second, we adjusted maximal channel conductances to obtain realistic cell firing characteristics in the final model (Fig. 2C). In some cases, we tried a large variety of possible parameters because many parameter choices would not give any cell firing at all. We used a variety of current-clamp studies in vivo, in slices, and in explant culture preparations to approximately match spike characteristics for pyramidal cells (Bindman et al. 1988; Connors and Gutnick 1990; Mason and Larkman 1990; McCormick et al. 1985; Ogawa et al. 1981; Wolfson et al. 1989; Woody and Gruen 1978). Final adjustments were made to produce repetitive bursting (Agmon and Connors 1989). These final adjustments to $\bar{g}$ were less than an order of magnitude for any one channel.

\section{Channels in the 3-channel model}

Unlike the 11-channel model, the 3-channel model was not constructed using basic voltage-clamp data. Active channels in the 3-channel model were limited to the Hodgkin-Huxley type fast sodium channel, $I_{\mathrm{Na}}$; a potassium delayed-rectifier channel, $I_{\mathrm{Kd}}$; and a slowly activating potassium current, $I_{\mathrm{K} s}$. Channel parameters for the fast sodium and delayed rectifier were those used by Traub (1982) for simulation of hippocampal pyramidal cells, slightly modified by Wilson and Bower (1989) for mitral cell simulations. The total channel current followed a Hodgkin-Huxley formalism

$$
\begin{aligned}
I_{\mathrm{HH}}=\bar{g}_{\mathrm{Na}} m^{3} h\left(V-E_{\mathrm{Na}}\right)+\bar{g}_{\mathrm{Kd}} n^{4}(V- & \left.E_{\mathrm{Kd}}\right) \\
& +\bar{g}_{\mathrm{Ks}} s^{3}\left(V-E_{\mathrm{Ks}}\right)+\bar{g}_{1}\left(V-E_{1}\right)
\end{aligned}
$$

where the terms on the right hand side represent $I_{\mathrm{Na}}, I_{\mathrm{Kd}}, I_{\mathrm{Ks}}$, and leak current, respectively, in $\mathrm{mA} / \mathrm{cm}^{2}$, with $\bar{g}_{\mathrm{Na}}, \bar{g}_{\mathrm{Kd}}$, and $\bar{g}_{\mathrm{Ks}}$ the corresponding maximal conductances, in $\mathrm{S} / \mathrm{cm}^{2} . E_{\mathrm{Na}}, E_{\mathrm{Kd}}$, and $E_{\mathrm{Ks}}$, the reversal potentials for the three currents, were $45,-90$, and $-77 \mathrm{mV}$, respectively.

The kinetic equations governing the states of the variables for the sodium channel had the following voltage dependence (in this and the following equations, voltage in $\mathrm{mV}$ and rate constants $\alpha$ and $\beta$ in $\mathrm{ms}^{-1}$ )

$$
\begin{aligned}
& \alpha_{m}=\frac{-0.32(V+52)}{e^{(V+52) /-4}-1} \quad \beta_{m}=\frac{0.26(V+25)}{e^{(V+25) / 5}-1} \\
& \alpha_{h}=0.128 e^{(V+48) /-18} \quad \beta_{h}=\frac{4}{e^{(V+25) /-5}+1}
\end{aligned}
$$

The delayed rectifier used a single activation variable $(n)$ that was raised to the fourth power. Its voltage-dependent $\alpha_{n}$ and $\beta_{n}$ functions are given by the following

$$
\alpha_{n}=\frac{-0.032(V+50)}{e^{(V+50) /-5}-1} \quad \beta_{n}=0.5 e^{(V+55) /-40}
$$


The slow $\mathrm{K}^{+}$channel was needed to provide a monotonically increasing current-frequency relationship (Fig. $1 B$ ). This channel was meant to perform the role of the afterhyperpolarizing conductances observed in cortical cells (Schwindt et al. 1988a). Much of this afterhyperpolarization appears to be due to calcium-sensitive potassium channels. Because we did not simulate calcium in the 3-channel model, we used instead a voltage-sensitive channel, the slow response of which mimicked the delay due to coupling through the calcium level. The state variable, $s$, was defined by use of the Borg-Graham formula (Eq. 2), with parameters 3.5, 0.8, 0.2, -46 , and 1 for $z, \gamma, \alpha_{0}, V_{1 / 2}$, and $\tau_{\min }$, respectively.

All three currents were always present in the model's initial segment and in some simulations were present in the soma as well. The dendrites were passive. Characteristic maximal conductances in the axon initial segment were $8.0,2.0$, and $20.0 \mathrm{~S} / \mathrm{cm}^{2}$ for $\bar{g}_{\mathrm{Na}}$, $\bar{g}_{\mathrm{Kd}}$, and $\bar{g}_{\mathrm{Ks}}$, respectively. Our choices of reversal potential and maximal conductance for $I_{\mathrm{Ks}}$ are interrelated. A lower reversal potential (equal to $E_{\mathrm{Kd}}$ ) and a smaller maximal conductance would provide the same driving force and would not alter the simulations. In some simulations, an active soma was included. In these cases, a lower maximal conductance could be provided by putting some or all of the $I_{\mathrm{Ks}}$ channels in the soma. The soma had individual channel conductances of $0.1,0.12$, and $0.2 \mathrm{~S} / \mathrm{cm}^{2}$, for $\bar{g}_{\mathrm{Na}}, \bar{g}_{\mathrm{Kd}}$, and $\bar{g}_{\mathrm{Ks}}$, respectively. The leakage conductance was $5 \cdot 10^{-5} \mathrm{~S} / \mathrm{cm}^{2}$, giving an input impedance of $\sim 70 \mathrm{M} \Omega$. Other values of these two parameters, including a lower leakage giving a far higher input impedance, did not significantly alter the behavior of this model.

\section{Channels in the 11-channel model}

Table 1 lists the channels that were simulated along with their density in the soma $(\bar{g})$. In the 11 -channel model, the soma was the only active compartment. There was no active initial scgment and the dendrites were passive. Table 1 also shows the parameters used for those channels that were defined using the Borg-Graham parameterization. Note that $\alpha_{0}=\beta_{0}$ in all cases. For those channels that show both activation and inactivation, the first row for that channel gives the parameters for the activation variable $m$, and the second row gives parameters for the inactivation variable $h$. The final three columns of the table give the temperature from which the kinetics were corrected $(T)$, the exponent (Exp) applied to the variable (for example, the activation variable for fast $\mathrm{Na}^{+}$is raised to the 3rd power: $\mathrm{m}^{3}$ ), and the reference to the paper from which the data were obtained, respectively. The temperature at which the experiment was done is important because the time constants for the channels can be expected to vary with temperature. In all cases we assumed a $Q_{10}$ of 3.0 and extrapolated to $37^{\circ} \mathrm{C}$.

SODIUM CHANNELS. The fast $\mathrm{Na}^{+}$and delayed rectifier used were almost identical to those of the 3-channel model, although the curves were fitted by use of the Borg-Graham formalism. Because of their rapid kinetics, they are relatively difficult to voltageclamp. We were able to fit a voltage-clamp study of fast sodium channel in hippocampal neurons (Sah et al. 1988), but we were unable to produce reasonable current-clamp traces with these parameters. We then tried varying our previous parameters for these two channels and discovered that these parameters primarily affected the shape rather than the timing of the action potential. The channel parameters that we used have a long history, deriving originally from Hodgkin-Huxley's original study in squid axon (Hodgkin and Huxley 1952), then altered by Traub (1982) for use in hippocampal pyramidal cell, subsequently varied by Wilson and Bower (1989) for simulations of olfactory mitral cell, and now altered once again for our use in a cortical pyramidal cell model.

A persistent sodium channel $\left(I_{\mathrm{NaP}}\right)$ has been clearly documented in cat sensorimotor cortex cells examined in vitro (Stafstrom et al. 1982, 1985). In these studies this current was difficult to separate from a calcium current and a slow outward current. Therefore we used a study done with single-electrode and whole-cell voltageclamp in dissociated hippocampal pyramidal cells and in hippocampal slices to provide the channel parameters (French et al. 1990). The neocortical cell study did not provide clear evidence for the size of this conductance. We observed model currentclamp behavior with a variety of channel densities and found that, if the conductance of the persistent $\mathrm{Na}^{+}$current were assumed to be high, it was impossible to repolarize the cell after a spike. Therefore we used a small value that did not prevent repolarization. This value is probably too low (Schwindt et al. 1990). The discrepancy may reflect some countervailing hyperpolarizing conductance that we are missing in the model.

POTASSIUM CHANNELS. A variety of potassium conductances has been observed in cortical cells (Schwindt et al. 1988a-c). These conductances have been divided into those producing fast, medium, and slow afterhyperpolarizations. The fast afterhyperpolarization has been shown to be due to two separate potassium conductances (Schwindt et al. 1988a), identified as corresponding to the delayed rectifier $\left(I_{\mathrm{Kd}}\right)$ and the A current $\left(I_{\mathrm{A}}\right)$. The $I_{\mathrm{A}}$ in neocortical cells (Zona et al. 1988) shows kinetics similar to the $I_{\mathrm{A}}$ observed in hippocampal pyramidal cell in slice preparation (Segal and Barker 1984). We therefore used the data from this hippocampal study to model $I_{\mathrm{A}}$. We used a delayed rectifier similar to that used in the 3-channel model as noted above.

Some of the medium and early slow afterhyperpolarizations described have been thought to be due to calcium-sensitive potassium currents (Schwindt et al. 1988b; Zona and Avoli 1989). There appear to be two types, distinguished by single-channel conductance, pharmacology, and voltage dependence (Latorre et al. 1989; Rudy 1988). The $I_{C}$ (or BK) channel is large, tetraethyl ammonium (TEA) sensitive, and voltage sensitive (Adams et al. 1982). The large-conductance calcium-sensitive channel that has been reported in rat neocortical cells in culture may be of this type (Zona and Avoli 1989). The $I_{\mathrm{AHP}}$ (or SK) channel is small, sensitive to apamin but not TEA, and not voltage dependent. An apamin-sensitive channel has been studied in cat sensorimotor cortex in slices (Schwindt et al. 1988c). A similar channel has also been reported in hippocampal cells (Lancaster and Adams 1986; Segal and Barker 1986). The approximate magnitude for these two currents taken together could be obtained from voltage-clamp studies in cat sensorimotor cortex (Schwindt et al. 1988a). However, the added complexity of calcium sensitivity makes kinetic analysis of these channels all the more difficult and therefore all the rarer. We could not find a good study of these channels in mammalian brain cells. We used a model of $I_{\mathrm{AHP}}$ developed by Pennefather et al. (1990) from data derived from frog sympathetic ganglion cells

$$
\alpha_{m}=200 \cdot[\mathrm{Ca}]_{\mathrm{i}} \quad \beta_{m}=0.014
$$

where $[\mathrm{Ca}]_{\mathrm{i}}$ is the concentration of calcium in the outermost shell (see below) in millimoles.

Our model for $I_{\mathrm{C}}$ was modified from one put forth by Moczydlowski and Latorre (1983) and included by Hines in the CABLE simulator. This model derives from data taken from rat muscle plasma membrane studied in artificial planar bilayers. We modified it so that it would show sensitivity to calcium concentrations of $50 \mathrm{nM}-5 \mu \mathrm{M}$, approximately the range of concentrations found in pyramidal cells (Regehr et al. 1989)

$$
\begin{aligned}
& \alpha_{m}=0.28 /\left(1+\frac{0.0011 \cdot e^{-0.84 \cdot V \cdot 2 \Im / R T}}{[\mathrm{Ca}]_{\mathrm{i}}}\right) \\
& \beta_{m}=0.48 /\left(1+\frac{[\mathrm{Ca}]_{\mathrm{i}}}{0.000011 \cdot e^{-V \cdot 2 \Im / R T}}\right)
\end{aligned}
$$


A sodium-dependent potassium current has also been noted in cat neocortical neurons (Schwindt et al. 1989). Because we did not simulate variation in intracellular sodium concentrations in our model, we did not include this channel. This current could play a role in offsetting the inward current due to the persistent sodium channel.

The late slow afterhyperpolarization in cortical neurons was shown to be sensitive to acetylcholine and is therefore likely to include the M-current, a muscarinically modulated potassium conductance (Schwindt et al. 1988b). M-currents have been demonstrated in neocortical neurons in human brain slices (Halliwell 1986) and in guinea pig cingulate cortex (McCormick and Prince 1985). The $I_{M}$ measured in human neocortex was reported to be similar to M-currents in other locations. We took results from a voltage-clamp study of guinea pig hippocampal pyramidal cells in slices to determine the parameters for this channel (Halliwell and Adams 1982).

The anomalous rectifier, $I_{\mathrm{AR}}$, is a mixed conductance that tends to prevent hyperpolarization of the cell. It passes both sodium and potassium ions, giving it an intermediate reversal potential of -50 $\mathrm{mV}, 15 \mathrm{mV}$ above resting potential. This conductance has been very well studied in cat sensorimotor cortical slices (Spain et al. 1987). It is the only channel in our model that was fully defined from information obtained in mammalian cortex.

CAICIUM CHANNELS. Three main types of calcium channels are generally recognized (Nowycky et al. 1985). These are the highthreshold, noninactivating $L$ current $\left(I_{L}\right)$; the high-threshold, inactivating $\mathrm{N}$ current $\left(I_{\mathrm{N}}\right)$; and the low-threshold, inactivating $\mathrm{T}$ current $\left(I_{\mathrm{T}}\right)$. These differences make it likely that the channels will play different roles in the activity of the cell. The clearest evidence for the existence of these three types of neurons in mammalian CNS comes from cell-attached membrane patch clamp in hippocampal neurons (Fisher et al. 1990). There is evidence for L channels in neocortical cells because calcium conductance has been shown to be decreased by dihydropyridines (specific blockers of these channels) in guinea pig neocortical cells (Constanti et al. 1985; Franz et al. 1986; Galvan et al. 1986). Additionally, T-channel conductance has been demonstrated in guinea pig parietal cortex slices (Friedman and Gutnick 1987) and in rat neocortical slices (Sutor and Zieglgänsberger 1987). The presence of an $\mathrm{N}$ channel is more difficult to ascertain, because it does not have the clear pharmacological marker of the $\mathrm{L}$ channel or the distinct voltage range for activation of the $T$ channel. We used voltageclamp studies for the kinetics of the $L$ and $T$ channel and the overall calcium current in a neocortical cell to estimate the contribution and kinetics of the $\mathrm{N}$ channel. The $\mathrm{T}$ channel was taken from a voltage-clamp study of rat thalamocortical relay neurons (Coulter ct al. 1989a). The L channel kinetics were derived from studies in guinea pig hippocampus pyramidal neurons (Eqs. 6 and 7 in Kay and Wong 1987)

$$
\alpha_{m}=\frac{1.6}{e^{-0.072(V-5)}+1} \quad \beta_{m}=\frac{0.02(V+8.69)}{e^{(V+8.69) / 5.36}}
$$

Voltage-clamp data of Sutor and Zieglgänsberger (1987) were used to determine both the approximate closing kinetics for the $\mathrm{N}$ channel and the relative density of the three channels. We could match the voltage-clamp data by using either of the inactivating currents, $\mathrm{T}$ or $\mathrm{N}$, to produce the decay from peak calcium current after a depolarizing voltage step. We tried both of these alternatives in the cell model. Making the decay entirely dependent on a large $T$-channel conductance produced an unstable resting potential. Any hyperpolarization reduced the large resting conductance contributed by the $T$ channel and thus led to further hyperpolarization. We therefore assumed that most of the inactivation of current was due to the $\mathrm{N}$ channel (Fig. $2 B$ ). The decay time for the total calcium current could then be used as the $\mathrm{N}$-channel inactivation time. The Goldman-Hodgkin-Katz current equation was used to calculate calcium current (Hille 1984). Therefore the maximal activations for these channels in Table 1 are given as permeabilities $(\bar{p})$ rather than conductances $(\bar{g})$.

In addition to ionic channels, several mechanisms were included to permit the removal of intracellular calcium (Carafoli 1987; Sala and Hernandez-Cruz 1990). The model used an implicit integration to allow radial diffusion of calcium as previously described by Moore and Hines (1986). Ten radial shells (calcium compartments) of uniform thickness were used, and the ratio of bound to free calcium was set at 200 ( $\beta$ in Eq. 3 of Moore and Hines 1986). Calcium concentration was modeled only in the soma; lateral diffusion of calcium was not simulated. All of the calcium-dependent mechanisms in the model use the concentration in the submembrane shell, represented as $[\mathrm{Ca}]_{i}$. A calcium pump (ATPase) and a $\mathrm{Na}^{+} / \mathrm{Ca}^{2+}$ exchange mechanism also contributed to calcium elimination. The latter mechanism was made nonelectrogenic because the net charge pumped was assumed to be compensated by the charge pumped by $\mathrm{Na}^{+} / \mathrm{K}^{+}$exchange. The charge moved by the calcium ATPase was small and was ignored. The equation used for the $\mathrm{Na}^{+} / \mathrm{Ca}^{2+}$ pump was taken from studies of cardiac cells (Kimura et al. 1987)

$\mathrm{I}_{\mathrm{Ca}_{\text {exchange }}}=-5 \cdot 10^{-6}\left([\mathrm{Na}]_{\mathrm{i}}{ }^{3}[\mathrm{Ca}]_{\mathrm{o}} e^{0.34 \cdot V 7 / R T}-[\mathrm{Na}]_{0}{ }^{3}[\mathrm{Ca}]_{\mathrm{i}} e^{-0.66 \cdot V 7 / R T}\right)$

Internal sodium, $[\mathrm{Na}]_{i}$, and external sodium, $[\mathrm{Na}]_{\mathrm{o}}$, concentrations were held constant at 10 and $140 \mathrm{mM}$, respectively. The external calcium concentration, $[\mathrm{Ca}]_{\mathrm{o}}$, was kept at $2 \mathrm{mM}$. The initial $[\mathrm{Ca}]_{\mathrm{i}}$ was $50 \mathrm{nM}$. We adopted the calcium ATPase used by Hines in CABLE

$$
\mathrm{I}_{\mathrm{Ca}_{\text {pump }}} \propto \frac{V_{\max } \cdot[\mathrm{Ca}]_{\mathrm{i}}}{k+[\mathrm{Ca}]_{\mathrm{i}}}
$$

with $V_{\max }=3.8 \cdot 10^{-11} \mathrm{mmol} \cdot \mathrm{ms}^{-1} \cdot \mathrm{cm}^{-2}$ and $k=10^{-6} \mathrm{mM}$.

Leakage conductance for most of the cell was $10^{-5} \mathrm{~S} / \mathrm{cm}^{2}$, with a conductance of $3 \cdot 10^{-4} \mathrm{~S} / \mathrm{cm}^{2}$ required in the soma to balance the resting conductances of the various active channels and provide the desired resting membrane potential. This gave an input impedance of $85 \mathrm{M} \Omega$. Resting input impedance was primarily due to the effects of channels active at resting membrane potential and could not be independently manipulated, although reduction of the anomalous rectifier would increase the apparent input impedance. This value is similar to input impedance values obtained from intracellular recordings using conventional microelectrodes (cell impalement). Recent studies of input impedance using whole-cell voltage-clamp have suggested much higher values (Edwards et al. 1989). Part of the discrepancy may be due to variation in the ages of the animals used (Storm 1990). In older animals, Storm obtained values of $\sim 200 \mathrm{M} \Omega$ with whole-cell clamp.

\section{RESULTS}

IPSPs produced phase-locking in our model pyramidal cell by affecting the instantaneous frequency of firing on each cycle. Phase-locking required that on each cycle the instantaneous frequency of a spontaneously firing cell be either increased or decreased so that the following spike occurred at the right time. Therefore we looked at the efficacy of IPSPs in producing frequency entrainment. When the firing of the pyramidal cell was being slowed, the interneuron was acting in a classically inhibitory manner. The transient hyperpolarizing current of the IPSP delayed the cell's firing by directly opposing the flow of ions into the cell. When the pyramidal cell firing rate was being accelerated by IPSPs, it was the intrinsic properties of the cell that permitted this paradoxical facilitatory effect. In recordings from cortical neurons, phase-locking occurs for only a few 

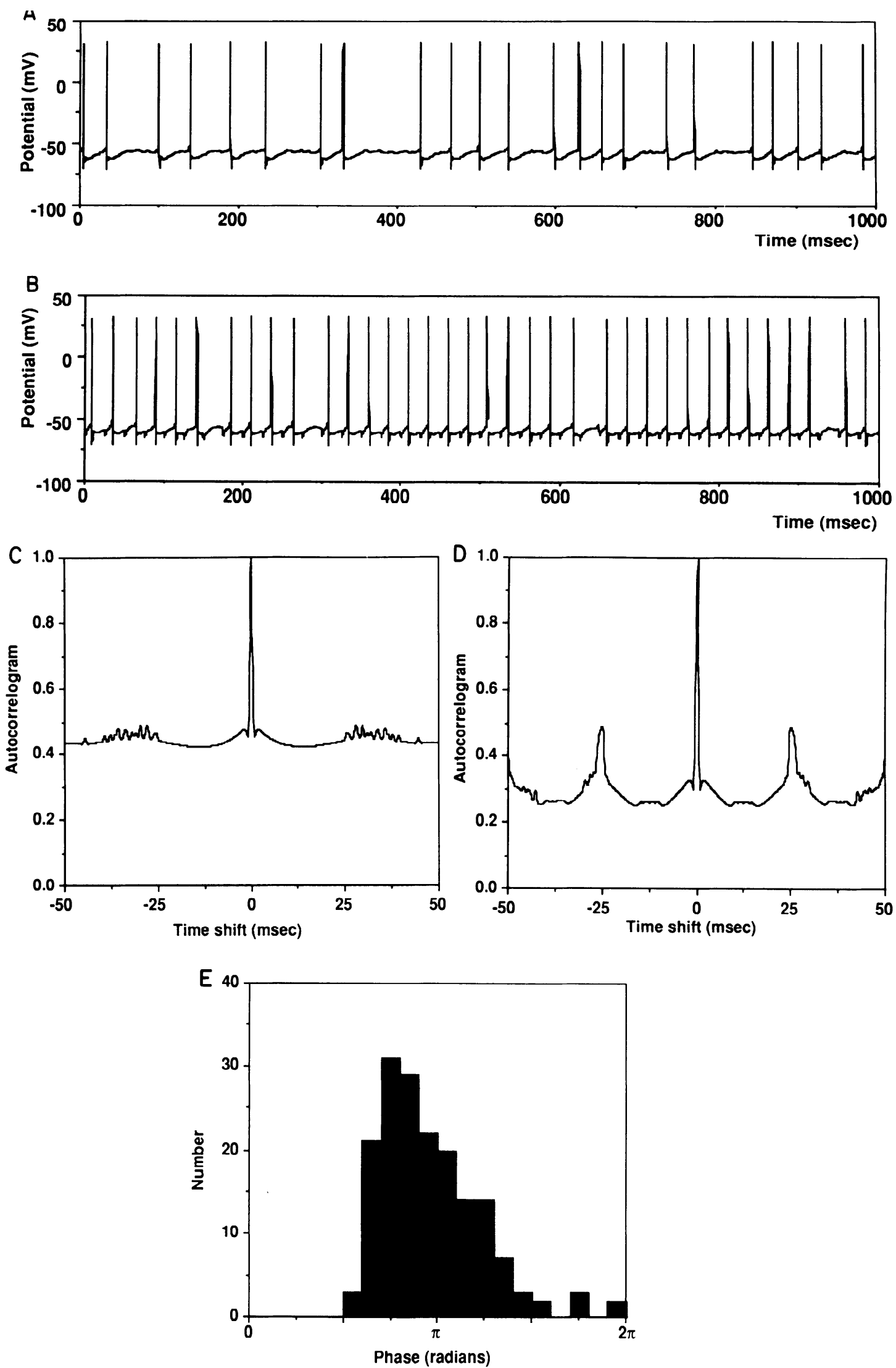

FIG. 3. Phase entrainment of the 3-channel model neuron receiving uncorrelated multisynaptic input into the apical dendrite. Maximal IPSP conductance was $50 \mathrm{nS}$. $A$ : membrane potential in the soma of a model neuron without inhibitory synaptic activity. $B$ : entrainment of the model neuron by use of $40-\mathrm{Hz}$ train of IPSPs. $C$ : autocorrelogram on $5 \mathrm{~s}$ of the model neuron voltage trace in $A$. With no IPSP, there is a slight correlation at $25-40 \mathrm{~ms}$. $D$ : autocorrelogram of $5 \mathrm{~s}$ of voltage trace with IPSP train of model neuron in $B$. Peak at $25 \mathrm{~ms}$ confirms the $40-\mathrm{Hz}$ spike entrainment. $E$ : histogram of phase lag of spikes relative to IPSP from voltage trace of model neuron in $B$ shows that spikes maintain a fairly constant phase with respect to the $40-\mathrm{Hz}$ IPSP train with a lag of $\sim 3 \pi / 4$. Phase relation of individual model neurons in a population would show a similar variation. 
hundred milliseconds at a time, suggesting that neuronal assemblies rapidly form and dissolve. In our simulations, however, we sought steady-state conditions to facilitate the analysis of firing properties and underlying mechanisms. The analysis of steady-state frequency entrainment is meant to provide insight into the mechanisms underlying phase-locking. Sustained frequency entrainment probably does not occur in neocortical pyramidal cells.

\section{Phase locking in the 3-channel model}

We simulated the effect of an IPSP train on a 3-channel model neuron receiving multiple uncorrelated synaptic inputs. The spike train without entrainment showed irregular firing (Fig. $3 A$ ). The very diffuse peak in the autocorrelogram demonstrated that there was minimal firing regularity (Fig. $3 C$ ). With the IPSP activated, the model neuron was closely entrained (Fig. 3, $B$ and $D$ ). The peak in the distribution of phase lag between IPSP and spike was $\sim 3 \pi / 4$ radians (Fig. 3E).

If two neurons with independent random excitatory inputs were entrained by the same inhibitory input, both cells showed an increased probability of firing at the same time, as demonstrated by the cross-correlation (Fig. 4). Such pairwise correlations in a large number of neurons would result in a local oscillating population field potential.

Recordings from current-clamped interneurons in cortical slices have shown that they respond to a constant depolarizing current injection with nonaccommodating spike trains at a higher frequency than is seen with pyramidal neurons (Chagnac-Amitai and Connors 1989; McCormick et al. 1985). Therefore we looked at the effect of a high-frequency IPSP train. We found that the model neuron entrained to the subharmonics of the inhibitory interneuron firing frequency (Fig. 5). With IPSP frequencies that are multiples of $40 \mathrm{~Hz}$, there was a peak in the autocorrelation corresponding to a frequency of $40 \mathrm{~Hz}$. In general, the dominant peak corresponded to the subharmonic closest to the mean frequency of the response to the uncorrelated synaptic activity alone. Lesser peaks in the autocorrelogram

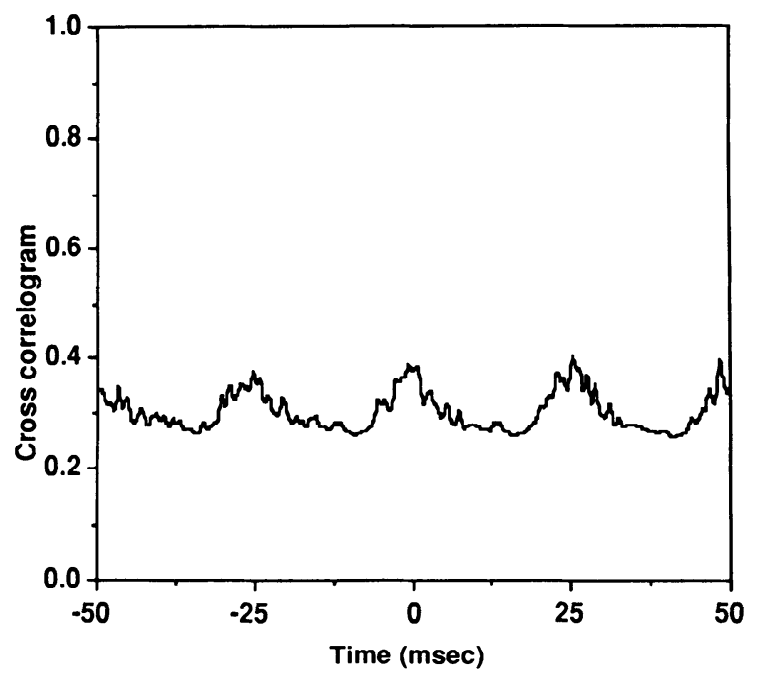

FIG. 4. Cross-correlogram between membrane potentials from 2 different 3-channel model neurons receiving an identical train of 5-nS IPSPs at $40 \mathrm{~Hz}$. Peak at $25 \mathrm{~ms}$ indicates a common frequency of $40 \mathrm{~Hz}$. corresponded to other subharmonics. Adding as much as $10 \%$ Gaussian noise to the inter-IPSP intervals did not prevent this entrainment.

\section{Frequency entrainment in the 3-channel model}

Given an adequate level of ongoing excitatory input, a compound IPSP of 20-100 nS could entrain the 3-channel model neuron to a frequency of $40 \mathrm{~Hz}$ (Fig. 6). Larger IPSPs were far more effective in entraining the follower cell than were smaller IPSPs. The model neuron was currentclamped over a range of $\sim 0.8-2.5 \mathrm{nA}$ to produce a constant firing rate from 30 to $50 \mathrm{~Hz}$. After the model had stabilized at the test frequency, a train of IPSPs was initiated in the proximal apical dendrite at the target frequency of $40 \mathrm{~Hz}$. With a 60 -nS IPSP, the model entrained perfectly for initial frequencies between $\sim 34$ and $47 \mathrm{~Hz}$ (Fig. 7). If the excitatory activity were outside this range, the initial frequency of neuron firing would be too far from the target frequency to produce perfect entrainment. When the initial frequency was too far below the target frequency, entrainment would occur for long stretches punctuated by a single dropped spike, giving a lower instantaneous frequency. During the time of entrainment, the phase relation between the inhibitory cell and the follower cell would gradually increase. In contrast, starting with an initial frequency too far above the target frequency produced no effective entrainment. Frequency entrainment, therefore, required a balance of tonic excitatory and phasic inhibitory input.

Phase-locking was produced with the inhibitory synapses located either on the apical dendrite, the soma, or the axon initial segment itself. The former two locations correspond to the regions where contacts are made by basket cells, whereas the latter is the target for contacts from chandelier cells. IPSPs onto the axon initial segment were slightly less effective in producing the frequency entrainment in all simulations. IPSPs onto proximal dendrite or soma were about equally effective. Entrainment occurred regardless of whether the reversal potential for the IPSP was set at resting membrane potential (shunting inhibition) or at the potassium reversal potential (hyperpolarizing inhibition) (see DISCUSSION).

\section{Repetitive bursting in the 11-channel model}

Pyramidal cells in cortex have many more channels than we included in our 3-channel model and show a much more complex repertoire of firing patterns, including bursting (Fig. 2). In contrast to neocortical cells that show a single burst under current-clamp (commonly called bursting cells) and regular spiking cells, repetitive bursting cells have not been thoroughly studied (Agmon and Connors 1989; Chagnac-Amitai et al. 1990; Silva et al. 1991). The observed synchronization of spike trains in visual cortex primarily occurs in such cells (Gray et al. 1991). The phase-locking involves the time of occurrence of the entire burst.

The 11-channel model pyramidal cell was adjusted to show repetitive bursting in response to depolarizing current-clamp. The frequency of bursting could be controlled with current injection within a range of $\sim 10-42 \mathrm{~Hz}$. (We define instantaneous bursting frequency as the inverse of the interbust interval measured from the 1st spike of one 


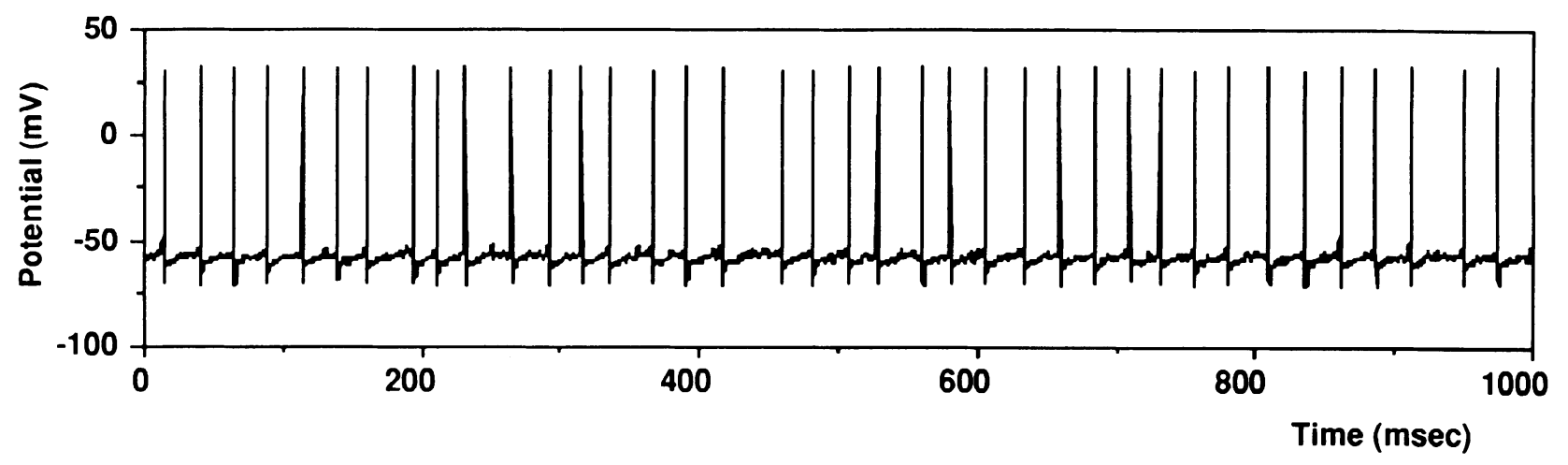

B

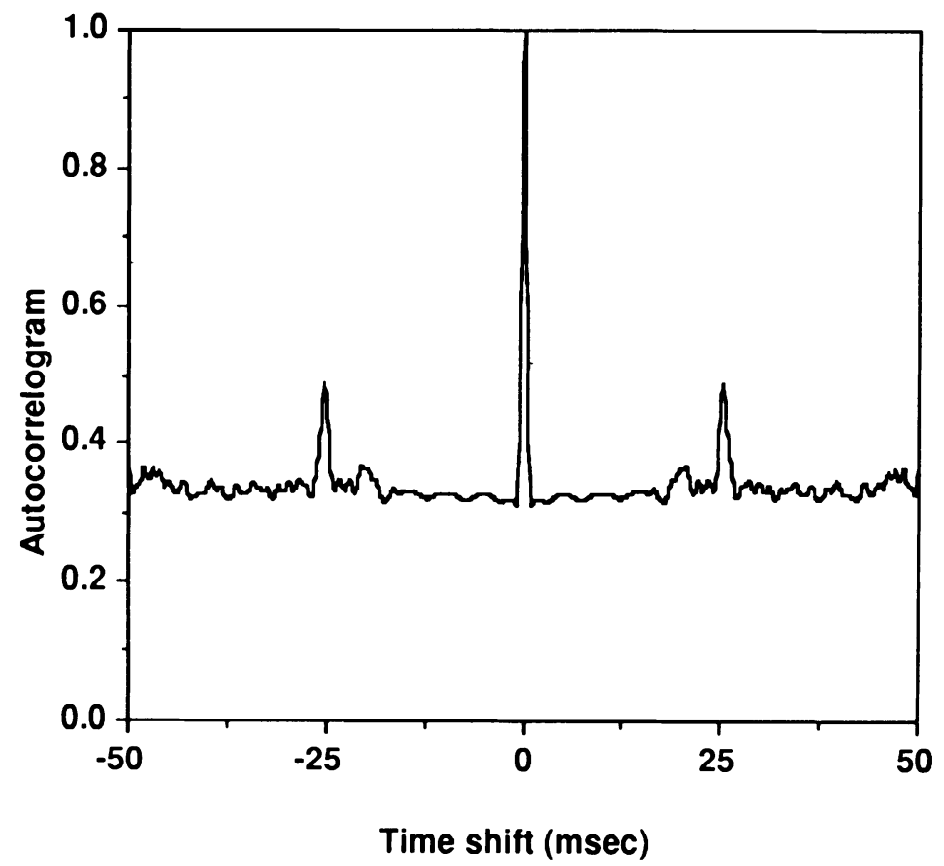

FIG. 5. Entrainment of 3-channel model cell receiving uncorrelated excitatory synaptic input into apical dendrite with 50 -nS IPSP train at $200 \mathrm{~Hz}$. A: membrane potential in soma of model neuron. $B$ : autocorrelogram of $5 \mathrm{~s}$ of voltage trace shows peak at $25 \mathrm{~ms}$. Smaller peak at $20 \mathrm{~ms}$ corresponds to $50-\mathrm{Hz}$ subharmonic.

burst to the 1st spike of the following burst.) Above this range, further increases in current produced a broadening of the burst, which allowed more calcium to enter. The increased $[\mathrm{Ca}]_{\mathrm{i}}$ caused greater activation of $I_{\mathrm{C}}$ and $I_{\mathrm{AHP}}$, which tended to produce greater interburst hyperpolarization and consequently a longer interburst interval. This tendency was balanced by the direct effect of the depolarizing current clamp, resulting in very little increase of burst frequency with increasing current injection beyond $\sim 1.2 \mathrm{nA}$.

\section{Frequency entrainment in the 11-channel model}

All simulations of entrainment by IPSPs for the 11-channel model employed a 90-nS inhibitory conductance with a reversal potential $10 \mathrm{mV}$ below resting, corresponding to the maximum $\mathrm{GABA}_{\mathrm{A}}$-mediated conductance at the reversal potential for chloride. The firing frequency of the model pyramidal cell could be accelerated from 34 to $40 \mathrm{~Hz}$ (Fig. $8 A$ ). We could not assess the range of deceleration to this frequency because we could not obtain bursting rates above $\sim 42 \mathrm{~Hz}$ with current-clamp. As shown in Fig. $8 B$, however, downward frequency entrainment will occur. In general, upward entrainment was not as robust with this model as in the 3-channel model. For example, entrainment from 36 $\mathrm{Hz}$ produced a complex firing pattern with an alternation of frequencies (Fig. 9, 2nd trace). At initial frequencies too low to obtain upward entrainment to $40 \mathrm{~Hz}$, the model tended toward the subharmonic frequency of $20 \mathrm{~Hz}$. The phase relation for the different initial frequencies is shown in Fig. 10. In all cases, the bursts are approximately in antiphase with the driving IPSPs. 


\section{Relative efficacy of IPSPs and EPSPs in phase-locking cells}

To assess the efficacy of phase-locking with IPSPs in the 11-channel model, we compared a pair of model pyramidal cells receiving uncorrelated synaptic input with pairs of pyramidal cells that received varying percentages of synchronized IPSPs or synchronized EPSPs. The synaptic input into the two identical pyramidal cells started at slightly different times so that the two model cells fired in antiphase. Five hundred excitatory synapses of $10 \mathrm{nS}$ each were scattered randomly throughout the distal apical dendrites. This is approximately equivalent to 5,000 excitatory synapses of $1 \mathrm{nS}$ each. One hundred inhibitory synapses of $1 \mathrm{nS}$ each were placed on the proximal apical dendrite. In the control situation, all synapses fired randomly according to a Poisson process with a mean frequency of $37 \mathrm{~Hz}$. The correlation peak at -17 ms shows that the two cells are approximately in antiphase (Fig. 11,0\% synchronized). The same simulation was then repeated with a percentage of either EPSPs or IPSPs converted from firing randomly to firing with a regular frequency of $33 \mathrm{~Hz}$. Cross-correlations of the voltage trace of the two model pyramidal cells show that both IPSPs and EPSPs were able to produce phase entrainment (Fig. 11). In the example shown, the IPSPs produced synchronization with a smaller proportion of synchronized PSPs (20 vs. $40 \%$ ). We assessed this phenomenon with three different 11-channel models, each of which used a completely different parameter set. In all cases, both EPSPs and IPSPs produced entrainment with $\sim 20-60 \%$ synchronization of either IPSPs or EPSPs. Because excitatory boutons onto the distal dendrites are $\sim 100$-fold more numerous than inhibitory boutons on the soma and proximal dendrite (Davis and Sterling 1979; Douglas and Martin 1990b), an individual inhibitory input may have far more effect in phase-locking the pyramidal cell. Adding synchronized IPSPs to synchronized EPSPs in this paradigm did not improve phase-locking beyond that seen with the same percentage of synchronized EPSPs or IPSPs alone.

\section{Mechanism of frequency entrainment}

The facilitatory effect of inhibition in the 3-channel model depended on the interaction of the hyperpolarizing potential with the slow potassium channel. Figure $12 \mathrm{~A}$ shows a sample voltage trace illustrating upward frequency entrainment. The arrows indicate the time of occurrence of IPSPs. We studied the interspike intervals $a$ and $b$ to determine the difference in dynamics that allowed interval $b$ to be shorter than $a$, giving a higher instantaneous frequency. We investigated the phase plane of total ionic current against voltage (Fig. 12B) because the rate of change of voltage with time is proportional to the total ionic current passing through the membrane (see equation in Fig. 12 caption). Each of the two trajectories entered from the bottom left and exited through the top of the graph. The individual data points on the curves were time points spaced $0.4 \mathrm{~ms}$ apart. Trajectory $a$, without IPSPs, showed a constant rate of depolarization illustrated by the constant distance between the time points on the trajectory. In trajectory $b$, the IPSP causes a loop to protrude to the right, involving a rapid outward current (top limb of loop) followed by hyperpolarization as the current decreases (bottom limb of loop).
After the IPSP, there is more inward current, and, consequently, the depolarization is more rapid (the time points are more widely spaced) than in trajectory $a$. This more rapid depolarization explains the briefer interspike interval.

This more rapid voltage rise was related to greater incoming current, which could be caused by two possible mechanisms: either the inward conductances are increased or the outward conductances are decreased. Both occur, but $>99 \%$ of the effect is caused by reduced conductance in the slow potassium channel, which turns off at hyperpolarized potentials. Figure $12 C$ shows a phase plane of $I_{\mathrm{Ks}}$ versus voltage. Trajectory $b$ shows a considerably smaller outward current during the period after the IPSP.

In the 11-channel model, acceleration in response to an IPSP train was due to a different set of mechanisms because a far greater variety of channels were present and bursts rather than spikes were being entrained. Effects at two different time scales, one corresponding to the period between bursts and the other to the period between spikes, interact to produce the overall behavior of the cell. The potassium conductances primarily responsible for determining the interburst interval in the model are the calcium-dependent channels, $I_{\mathrm{C}}$ and $I_{\mathrm{AHP}}$. The former is known to be voltage as well as calcium dependent, whereas the latter is believed to be only calcium dependent. Therefore hyperpolarization does not greatly increase these potassium conductances in the way that it increased the slow potassium conductance in the 3-channel model. Instead, the frequency increases because of an extensive shift in dynamics that changes the bursts as well as the interburst intervals. As shown in Fig. 13, the bursts in the presence of the IPSPs (Fig. 13A) contain fewer spikes than do those in the absence of IPSPs (Fig. $13 B$ ). As a result, there is less entry of calcium during the burst, as can be seen in the phase plane (Fig. 13C). The reduced calcium entry produces less potassium conductance in the calcium-sensitive potassium channels, which results in a shorter interburst interval and an increased frequency. In the model, the primary effect is mediated by $I_{\mathrm{C}}$. However, the exact calcium sensitivity and density of the two calcium-sensitive voltage channels remain uncertain, so that $I_{\mathrm{AHP}}$ could be of equal or greater importance.

\section{DISCUSSION}

We have demonstrated two different mechanisms whereby large IPSPs could phase-lock and frequency-entrain cortical neurons. These mechanisms depend on the voltage and calcium dependence of active membrane conductances. The results are robust, having been found in many simulations with a wide variety of channel parameters. There were, however, limitations to how accurately we were able to model cortical neurons. Although we do not believe that these limitations invalidate our general conclusions, we provide a detailed discussion to aid in future studies. Many of these limitations could be reduced by closer coupling between experimental and modeling studies.

\section{Neural constraints}

The 11-channel model was chosen to mimic the firing of a subclass of repetitive bursting pyramidal neurons that 


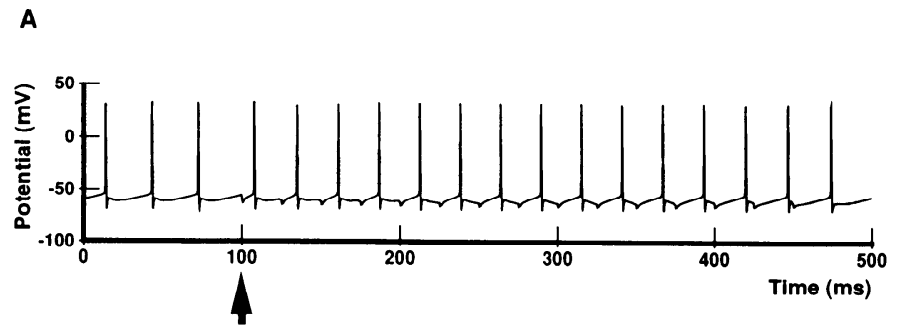

B

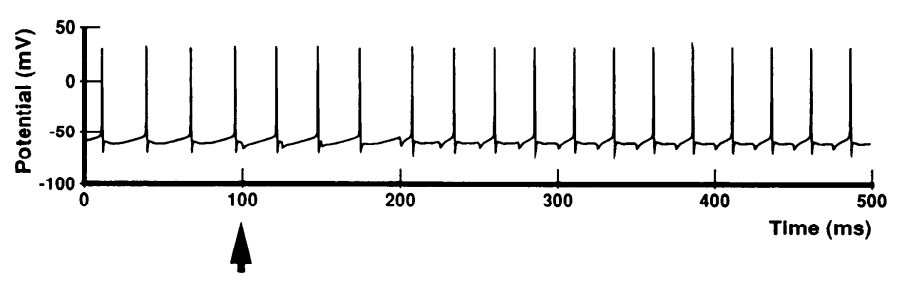

C

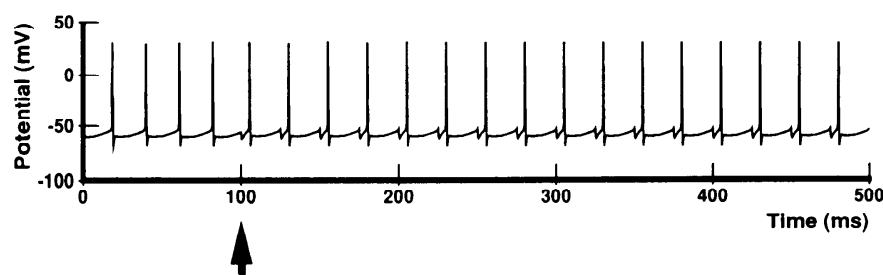

FIG. 6. Entrainment of a 3-channel model neuron firing at constant frequency to a $40-\mathrm{Hz}$ train of $60-\mathrm{nS}$ IPSPs. IPSP train started at $100 \mathrm{~ms}(\mathrm{t})$. $A$ : partial upward entrainment from $34.2 \mathrm{~Hz}$. IPSP was not powerful enough to fully entrain the cell from this frequency. During the interval shown, the phase relation between IPSP and spike increased progressively. A dropped spike followed shortly after $500 \mathrm{~ms}$, as shown in Fig. 7. $B$ : acceleration of firing from 35.7 to $40 \mathrm{~Hz}$. C: deceleration of firing from 47.2 to $40 \mathrm{~Hz}$.

have been observed in cerebral cortex (Agmon and Connors 1989; Bush and Douglas 1991; Chagnac-Amitai et al. 1990; Gray et al. 1991; Silva et al. 1991). However, the values of many parameters remain uncertain. Although these values were obtained from voltage-clamp studies, the studies were not, of course, all done on a single cell. An initial concern was that the large number of parameters available would allow one to model any desired cell behavior in the same way that one can fit any continuous curve with a sufficiently complex polynomial. Our experience with the 11-channel model did not substantiate this, because we were not able to duplicate in the 11-channel model the same mechanism of spike frequency entrainment seen in the 3-channel model despite trying over the course of $\sim 300$ simulations. However, we were able to produce repetitive bursting with three very different sets of parameters. Interestingly, all three of these models showed similar entrainment and phase-locking. There may be many other possible models in widely separated areas of parameter space that exhibit the same behavior.

The difficulties that we encountered in attempting to build a realistic neocortical pyramidal cell model were caused by limitations of modeling techniques, by limitations in the type of data available, and ultimately by the extraordinary complexity of a single neuron. Although our 11-channel model contained many mechanisms that the 3-channel model lacked, it was still highly simplified relative to a real cortical pyramidal cell. Except for calcium, second-messenger mechanisms as well as external modulators were not included. For example, we used $I_{M}$ in the model, but had no way of evaluating the amount of acetylcholine likely to be present in the cell environment that would modulate this current.

The voltage-clamp data we used to determine our parameters necessarily came from a variety of sources and thus provided only an approximation to the true behavior of channels in a bursting cat visual neocortical cell. Although we attempted to use voltage-clamp data from neocortical cells of mammals, in some cases we used data from other cell types or from other animals. Even the available mammalian cortical cell data were collected from different cortical areas in different species under a variety of conditions. Furthermore, within one cortical area of one species, various types of cells with different physiological properties that reflect different underlying channel densities or dynamics may be sampled (Chagnac-Amitai et al. 1990).

Voltage-clamp studies differ in technique and in the condition of the cells studied. First, some studies were done with cell impalement, whereas others were done with whole-cell clamp recording. The latter technique has the advantage of permitting more rapid passage of current, allowing channels with fast kinetics to be voltage-clamped. However, this technique has the disadvantage of dialyzing the cytoplasm, which may remove second messengers critical to maintaining the conductance or kinetics of the channel being studied. Second, voltage-clamp studies can be done in slices, in acutely dissociated cells, or in tissue culture. The first type of study is likely to give cells that are relatively close to their native state but provides poor voltage control of dendrites. Acutely dissociated cells are generally shorn of their dendrites; voltage-clamp of such cells omits dendritic conductances but permits more accurate measurement of somatic conductances. Cultured cells may undergo a process of dedifferentiation that will change the amount and perhaps even the type of channels expressed in their membrane. Third, voltage-clamp study of single conductances is dependent on manipulating the cell's environment to eliminate extraneous conductances and isolate the conductances of interest. Studies of a single current may be done with different blockers or different manipulations that may inadvertently alter the channels being investigated. For example, calcium channels can be blocked by organic agents or by $\mathrm{Cd}^{2+}$ or can be rendered nonconducting by simply removing calcium from the extracellular medium. These different manipulations may also have effects on other channels that maintain a low level of conductance despite pharmacological blockade designed to eliminate their effects. Fourth, some voltage-clamp studies are done at room temperature and some at body temperature. There is generally no consistent factor that will allow prediction of the conductance at various temperatures. Although we assumed a single $Q_{10}$ to normalize the biophysical parameters for all of the channels we used, this is inadequate to describe the temperature dependence of many channels (see Fig. 14 of Sah et al. 1988) or even to describe temperature dependence of the same type of channel across species (Chiu et al. 

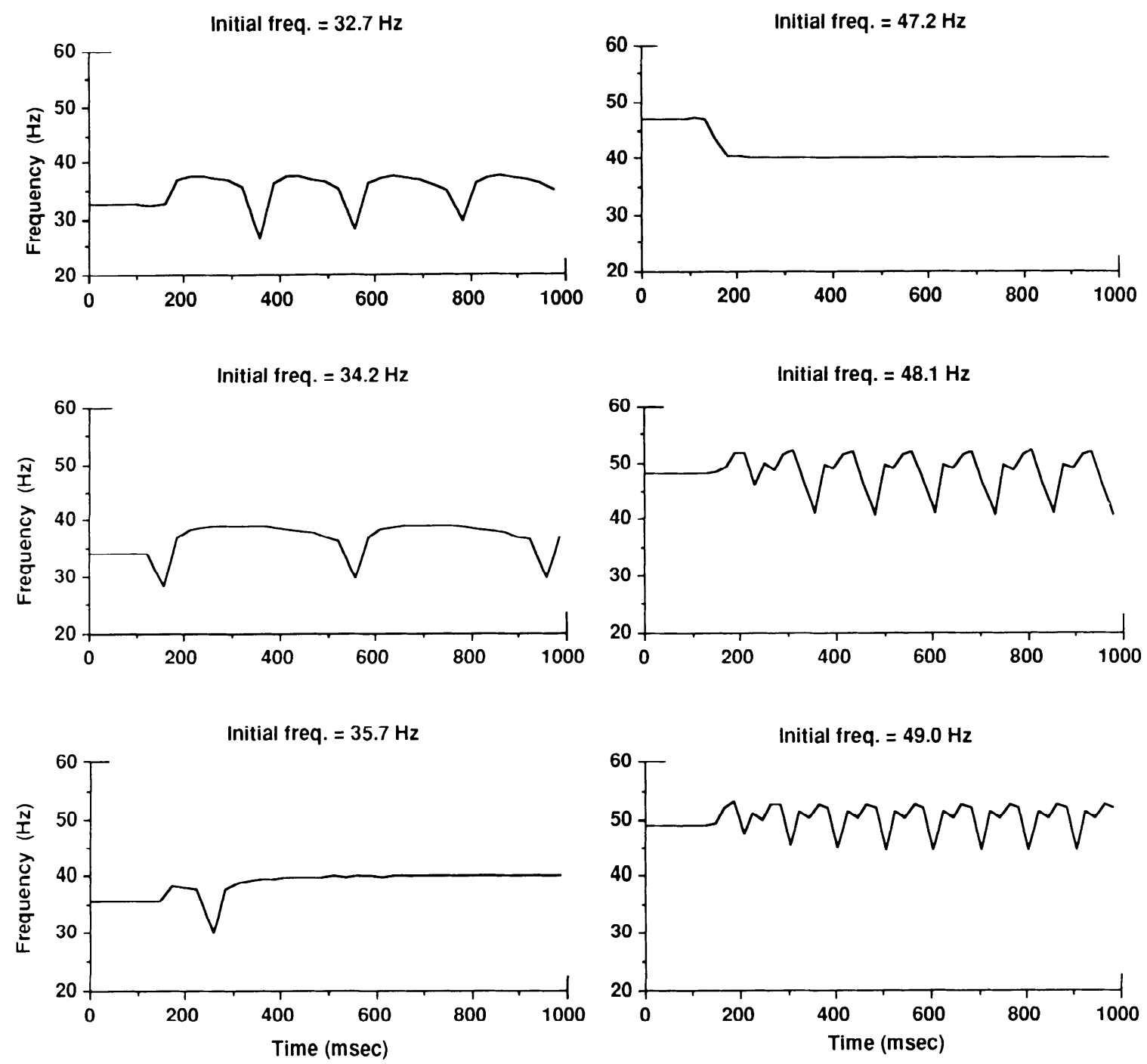

FIG. 7. Effect of IPSPs on instantaneous frequency of spiking (inverse of the interspike interval) of the 3-channel model at 6 initial frequencies. Simulations were identical to those in Fig. 6. Current-clamped model neuron received a compound IPSP with maximal conductance of $60 \mathrm{nS}$ at a frequency of $40 \mathrm{~Hz}$. The $1 \mathrm{st}$ IPSP occurred at $150 \mathrm{~ms}$. Complete entrainment was seen between 35.7 and $47.2 \mathrm{~Hz}$. At initial frequencies too low to be fully entrained, the instantaneous frequency stayed near the entraining frequency. Phase difference between IPSP and spike gradually lengthened until a spike was missed, giving a longer interspike interval corresponding to a low instantaneous frequency. At higher initial frequency, the spikes were not partially entrained in this way.

1979). Given these problems, it is not surprising that the voltage-clamp data could not be used to synthesize a model neuron that showed a reasonable response to current-clamp without some adjustment of the parameters. Until some of these methodological problems are confronted, it will remain difficult to integrate the information obtained from different studies.

The location and differential density of channels in neuronal membranes is also problematic but could be approached by the use of immunohistochemical staining as monoclonal antibodies against various channels become available (Hendry et al. 1990). Even with this technique, some means of in situ physiological identification of channels will still be desirable because differential aggregation of protein subunits could provide families of channels with different kinetics that might share the same epitopes (Hartmann et al. 1991; Ruppersberg et al. 1990). In our 3-chan- nel model, we were able to produce similar spiking behavior and response to inhibition with channels in the axon initial segment alone, the soma alone, or in both axon initial segment and soma. Therefore in the 11-channel model we only included channels in the soma. Sodium channels have also been demonstrated in dendrites of cortical pyramidal cells, but whether their concentration is sufficient to produce dendritic spikes remains unknown (Huguenard et al. 1989). The effects of EPSPs generated in the distal dendrite would be far different from those considered here if dendrites are capable of generating action potentials. However, our conclusions with regard to the effects of IPSPs would be expected to be little changed because of their proximal location.

Despite the many approximations that were made to arrive at the 11-channel model, it exhibits many of the properties that are observed in real bursting neocortical neurons 
A

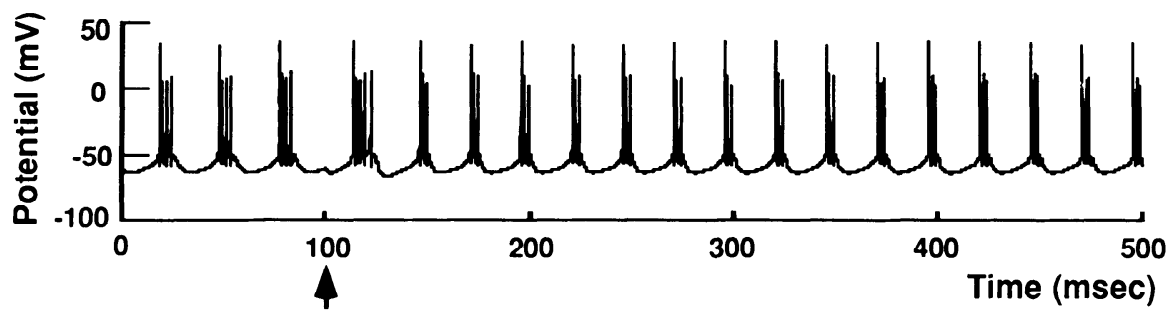

FIG. 8. Frequency entrainment of the 11-channel model. Onset of IPSPs was at $100 \mathrm{~ms}(\uparrow)$. Maximum conductance of the IPSP was $93 \mathrm{nS}$. $A$ : initial frequency of $34 \mathrm{~Hz}$ entrained upward to $40 \mathrm{~Hz}$. $B$ : initial frequency of $38 \mathrm{~Hz}$ entrained downward to $33 \mathrm{~Hz}$. These lower frequencies were assessed because it was not possible to drive the cell faster than $\sim 42 \mathrm{~Hz}$ with current clamp.

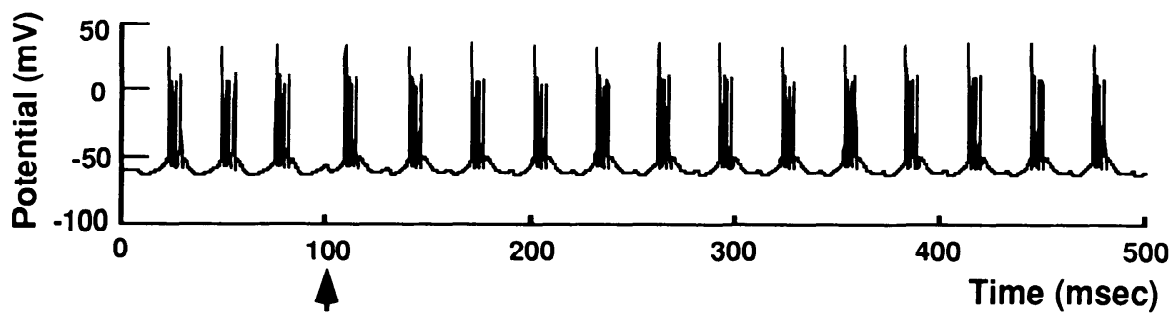

and it may be the most detailed model of a neocortical neuron ever attempted. However, because of the many uncertainties involved, we do not regard our 11-channel model as a "realistic" model that supercedes the 3-channel model. Instead, both models illustrate mechanisms at the channel level that produce an effect of interest at the neuron level. The presence of IPSP-mediated phase-locking in two very different models suggests that the phenomenon could occur in a variety of cells.

\section{Comparison of 3-and 11-channel models}

The two models highlight two different mechanisms that might contribute to frequency entrainment. A major difference between them is due to the presence of calcium and calcium-mediated potassium conductances in the 11-channel model.

In the 3-channel model, the entrainment is caused mainly by the effect of membrane potential changes on one particular channel. This effect is analogous to anode break, cell spiking on release from sustained hyperpolarization (Moore et al. 1989). In this model, however, the hyperpolarization would be too small to give an anode break effect if applied to a quiescent cell. It was effective in this setting because the cell was already firing actively because of ongoing activation from current injection or from the activation of excitatory synapses. The cell was poised to fire and needed only a small push to either speed it up or to slow it down. A hyperpolarizing IPSP was effective in producing this push. Shunting IPSPs would not have been effective if they had produced no hyperpolarization because they would then have had no effect on the state of the voltagesensitive channels. In fact, in the 3-channel model, we assumed passive chloride distribution giving a $\mathrm{GABA}_{\mathrm{A}}$ reversal potential equal to resting membrane potential. Nonetheless, IPSPs were effective in entrainment because they provided a relative hyperpolarization from the depolarized state produced by current clamp or EPSPs. We assumed that redistribution of passively distributed ions would occur with a relatively long time constant, maintaining the ion gradient and the resulting reversal potential nearly constant during the course of an IPSP. In the 11-channel model, we

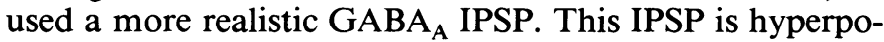
larizing from resting potential since chloride is not passively distributed but has a resting potential approximately $10 \mathrm{mV}$ below the resting membrane potential of a cell (Thompson et al. 1988).

In the 11-channel model, the anode break mechanism did not occur for two reasons. First, the firing frequency in this model depended as much on calcium-dependent as on voltage-dependent mechanisms. Therefore a transient change in voltage was not as effective in changing the firing frequency. Second, in this model we were studying frequency entrainment of bursts rather than spikes. Nonetheless, the underlying effect seen in the 3-channel model, a paradoxical increase in inward current after hyperpolarization, was observed in the 11-channel model as well. In the latter, in addition to decreasing outward current through the $I_{C}$ potassium channel, hyperpolarization also directly increased inward current through the anomalous rectifier. It may be that these effects would be more pronounced in the 11-channel model if it were altered to produce regular spiking instead of bursting.

Although we were able to determine part of the mechanism of upward frequency entrainment, two-dimensional phase plane analysis was less revealing in this setting because of the many more variables involved. Because the effects of various channels do not add linearly, it is impossible to assign a straightforward role to single channels. Attempts to analyze the system by evaluating its response to removal of a particular channel were unrevealing because removal of a conductance tended to produce a cell that showed completely different behavior, such as loss of bursting. 
Initial freq. $=34 \mathrm{~Hz}$

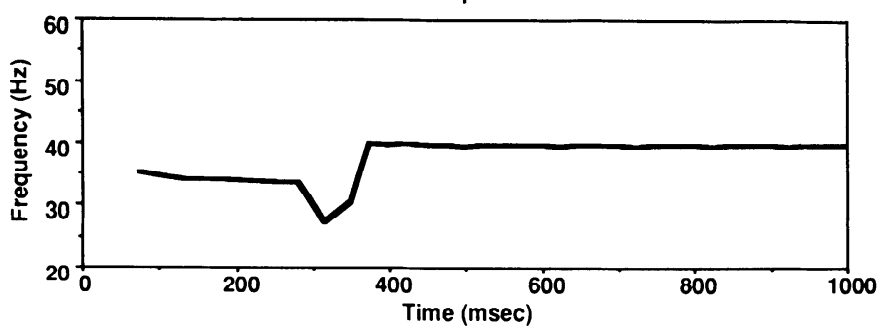

Initial freq. $=36 \mathrm{~Hz}$

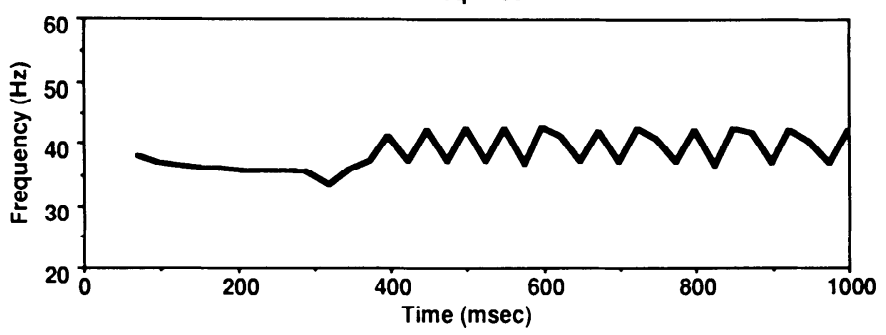

Initial freq. $=40 \mathrm{~Hz}$

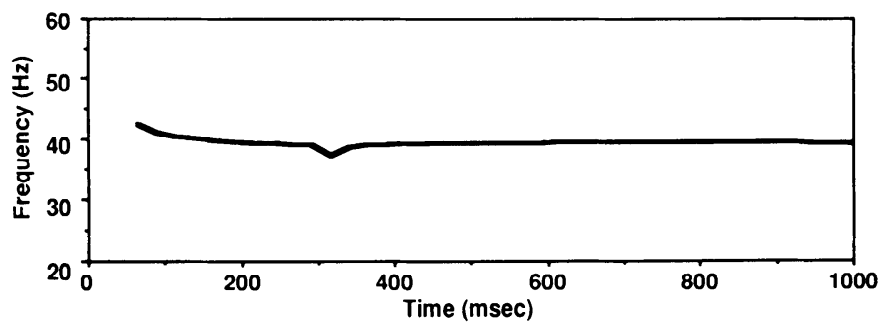

Initial freq. $=45 \mathrm{~Hz}$

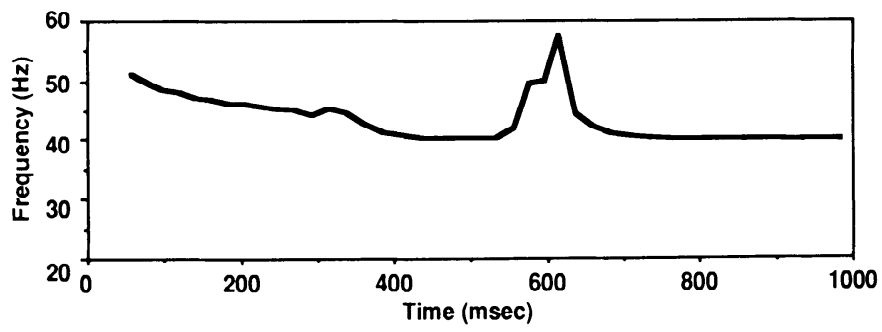

FIG. 9. Effects of IPSPs on the instantaneous frequency of bursting (inverse of the interburst interval measured between the initial spikes of sequential bursts) of the 11-channel model at 4 initial frequencies. IPSP trains began at $300 \mathrm{~ms}$. Frequency entrainment was not as robust as in the 3-channel model, as illustrated by the partial upward entrainment from 36 $\mathrm{Hz}$, which varied between 37,40 , and $42 \mathrm{~Hz}$. Bottom: downward entrainment from a declining baseline, a consequence of the difficulty of driving this cell at a rapid burst frequency.

\section{Types of inhibitory interneurons involved}

The location of inhibitory synapses near the soma makes them particularly effective in producing precise timing of inputs for phase-locking. In a passive dendritic tree, there will be significant broadening of PSPs initiated in the distal dendrites, where excitatory synapses are found. PSPs generated near the soma, the site of inhibitory synapses, will show relatively little broadening. This can be expected to improve timing precision and might allow all of the pyramidal neurons contacted by a single inhibitory neuron to be synchronized more rapidly.
There are a variety of interneurons in cortex that could help entrain pyramidal neurons through this mechanism. Two types of interneurons that show distinct patterns of connectivity are basket cells and chandelier cells (Kisvarday et al. 1987; Martin et al. 1989; Somogyi et al. 1983a,b). Both interneurons typically synapse on 50-200 pyramidal neurons. Axons of basket cells extend up to $1 \mathrm{~mm}$ from their cell bodies, whereas those of chandelier cells extend only $100-300 \mu \mathrm{m}$. Basket cells synapse onto pyramidal cell bodies and proximal apical dendrites, whereas chandelier cells synapse exclusively on axon initial segments. In the 3-channel model, we assessed the effects of IPSPs at different sites to determine the relative efficacy of basket cells and chandelier cells in entraining pyramidal neurons. Synapses on the axon initial segment were less effective because entrainment depends on hyperpolarization and not conductance change in accelerating firing in the postsynaptic cell. A local conductance change in the axon initial segment appeared to interfere slightly with the initiation of the action potential. A much more powerful inhibition at the axon initial segment would completely prevent firing. Inhibition of this magnitude could be used to produce entrainment through periodic blockade of firing.

IPSP entrainment was effective in the 11-channel model

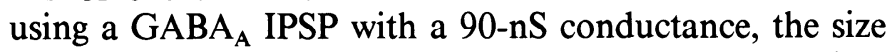
measured from a population IPSP in neocortex in vitro (Connors et al. 1988). Therefore entrainment by IPSPs would require a population of inhibitory interneurons projecting onto the postsynaptic excitatory cells. Because pyramidal neurons often have excitatory projections back to the same population of inhibitory neurons, the circuit could produce such a resonance (Andersen and Andersson 1968; Bush and Douglas 1991). IPSPs could also be important in entraining the interneurons themselves if they are reciprocally interconnected.

Inhibitory conductances mediated by $\mathrm{GABA}_{\mathrm{B}}$ receptor tend to be slow hyperpolarizing conductances located in the dendrites (Dutar and Nicoll 1988). GABA $A_{A}$ conductances are rapid shunting conductances located in the proximal dendrite and cell body (Scharfman and Sarvey 1987). IPSP entrainment would be likely due to a $\mathrm{GABA}_{\mathrm{A}}$ mechanism because the time course, voltage change, and location are all suitable.

\section{Possible sites of IPSP entrainment}

Recently, recordings of pyramidal cells in visual cortex have shown phase-locking of cell firing lasting several hundred milliseconds and extending over several millimeters of cortex in response to visual stimulation (Gray et al. 1989; Gray and Singer 1989). It has been suggested that the resulting oscillations may play a role in grouping together neurons responding to different aspects of a single stimulus. This phase-locked firing involves pyramidal neurons firing short, high-frequency bursts spaced at $20-30 \mathrm{~ms}$ (Gray et al. 1991).

Inhibitory interneurons in guinea pig frontal cortex show an intrinsic $40-\mathrm{Hz}$ rhythmicity in response to currentclamp (Llinás and Grace 1989; Llinás et al. 1991; Walton et al. 1990). This intrinsic rhythmicity could allow them to 


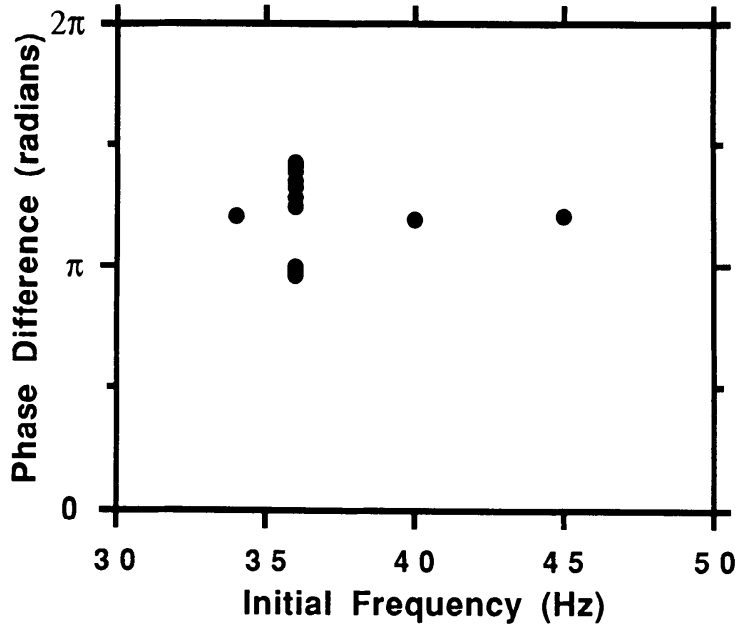

FIG. 10. Final phase difference between the IPSP and spike firing as a function of initial frequency for the 11-channel model. Phase was measured from the beginning of the IPSP to the 1st spike of the burst. Multiple phase values for $36-\mathrm{Hz}$ initial frequency correspond to the phases of the various instantaneous frequency shown in the 2nd trace of Fig. 9. serve as pacemakers for cortical oscillations. Ferster (1986) studied the occurrence of EPSPs and IPSPs in orientationsensitive pyramidal neurons in visual cortex of cat during visual stimulation. He demonstrated that both EPSPs and IPSPs occur primarily when the cell is activated with the preferred orientation, concluding that the tuning was not the result of inhibition predominating at the null orientation. The IPSPs seen during activation were brief and rhythmic, as required by our hypothesis (Fig. 14). This result has been confirmed by Sato et al. (1990), who observed IPSPs in cortical area VI at the peak of response to both optimal stationary and moving stimuli. These results, in combination with those of the present study, suggest a role for inhibitory interneurons in phase-locking in visual cortex. This hypothesis could be tested by local iontophoresis of GABA blockers near cell somata during induction of oscillations by visual stimuli.

Phase-locking with IPSPs may also be important in other areas of the CNS. Rhythmic population firing is also seen in the thalamus. Spindling, a $10-$ to $14-\mathrm{Hz}$ rhythm, involves the reticular nucleus, an area containing purely inhibitory
IPSPs
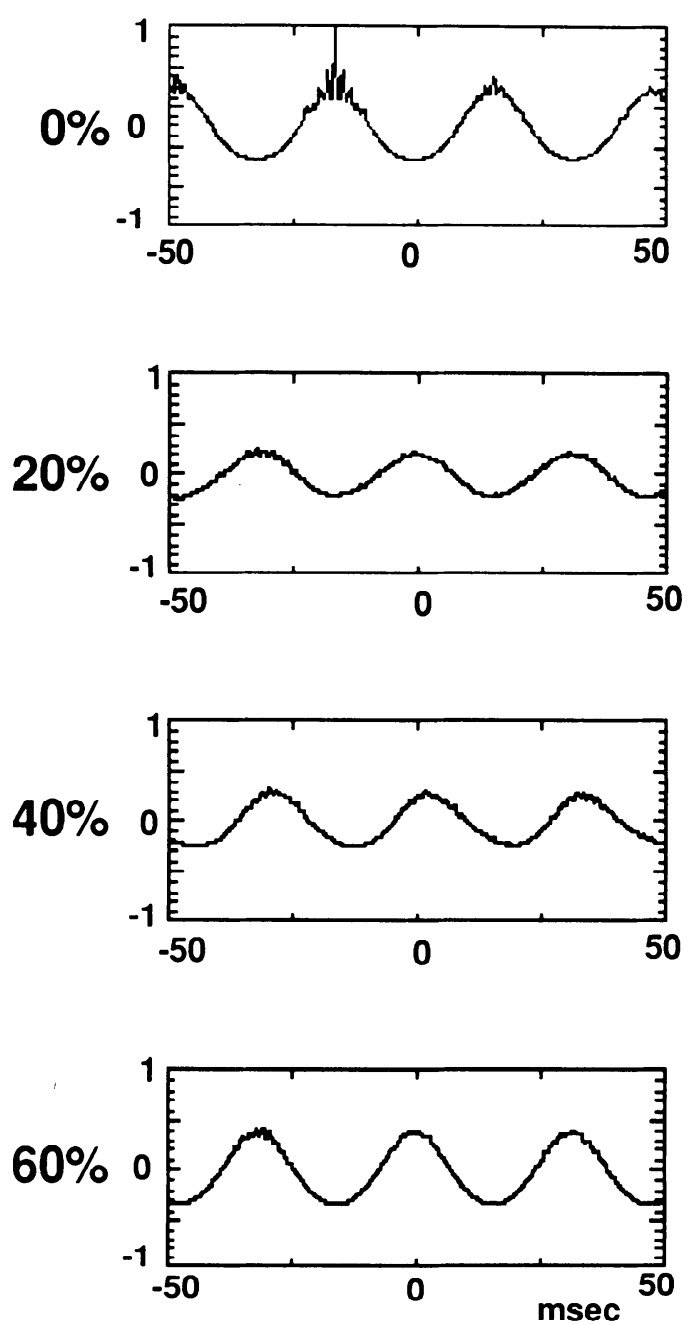

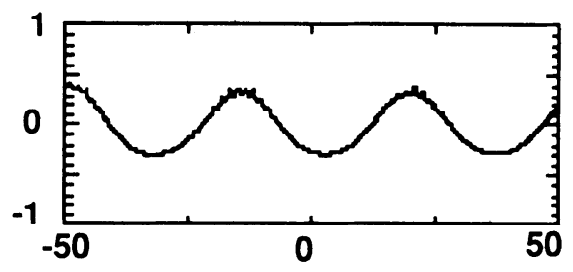

\section{EPSPs}
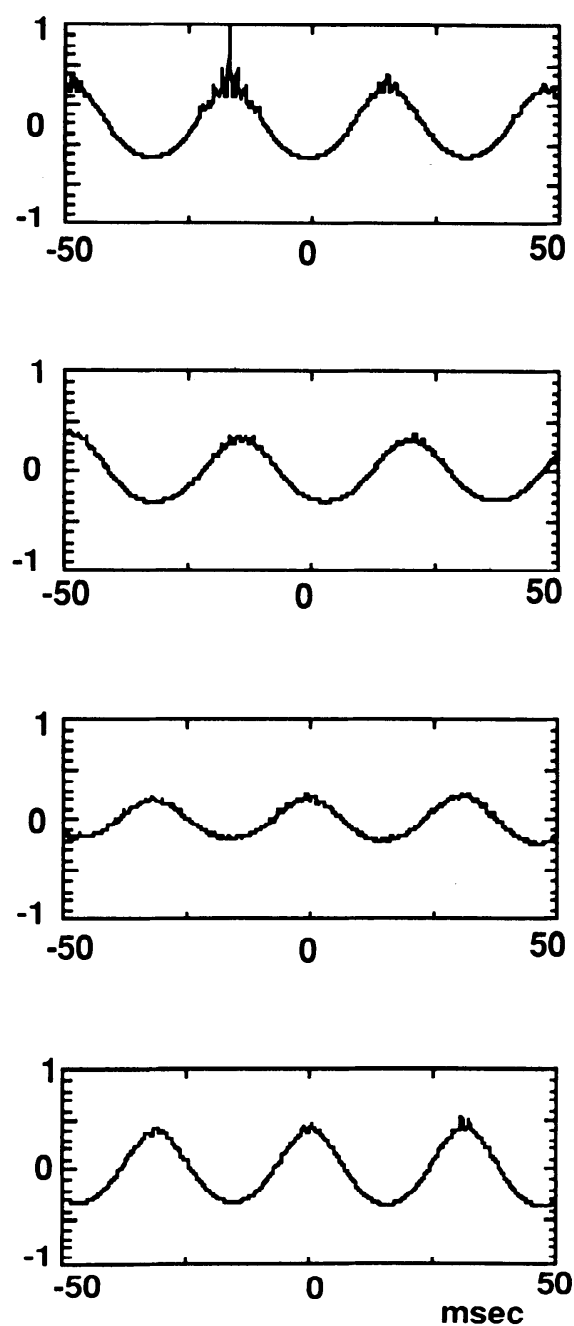

FIG. 11. Comparison of entrainment by EPSPs vs. IPSPs. Cross-correlations between two 11-channel model neurons initially firing in antiphase. Cells were both exposed to 500 EPSPs and 100 IPSPs, most of which fire at random. A certain percentage of either the EPSPs or the IPSPs fired periodically at $33 \mathrm{~Hz}$ (30-ms period). This percentage is given on the left. The 2 traces on the top row are identical and show a prominent negative peak at $-17 \mathrm{~ms}$, approximately antiphase. In the 2 nd row, with $20 \%$ periodic PSPs, the model cells receiving periodic IPSPs were synchronized (note peak at 0 $\mathrm{ms}$ ), whereas the model cells receiving periodic EPSPs were not. At higher percent periodic PSPs, the synchronization was similar with either periodic EPSPs or periodic IPSPs. 
A
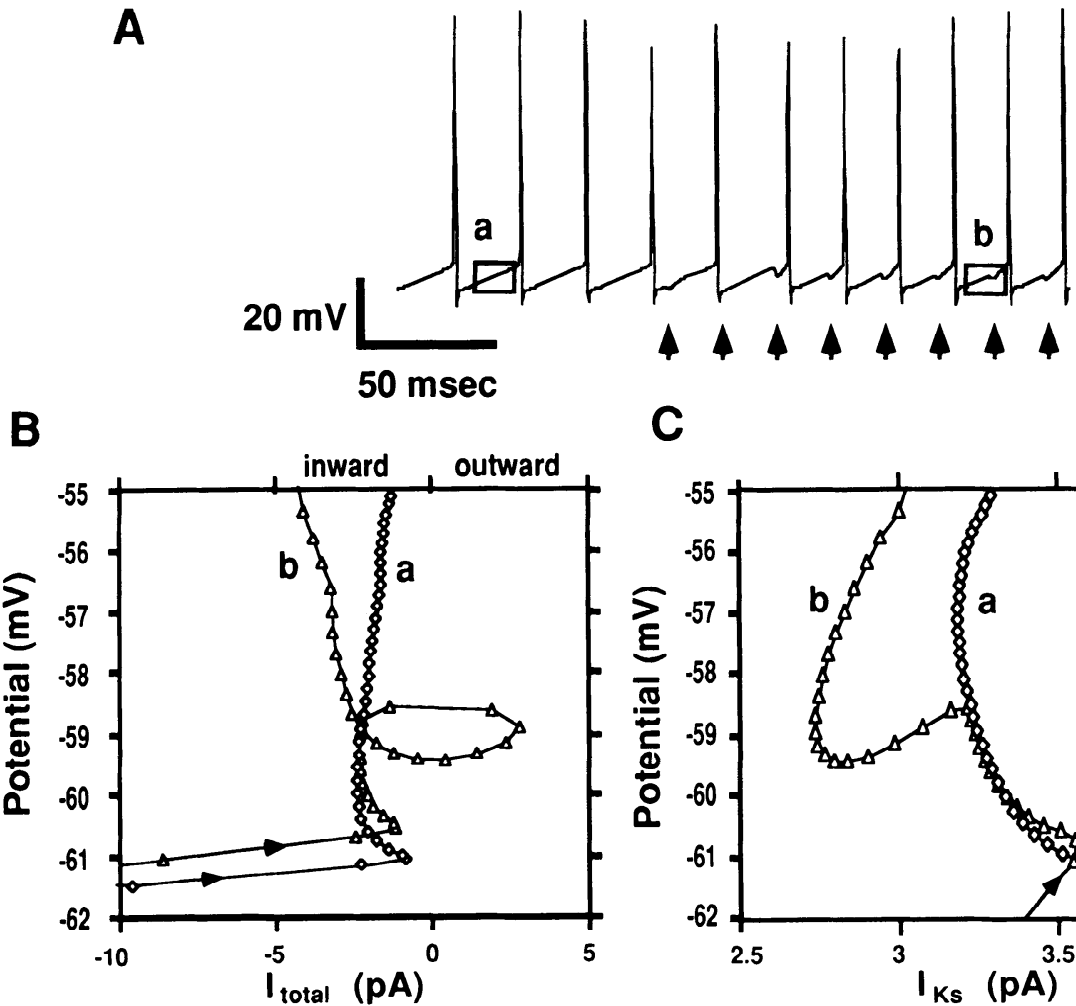

C

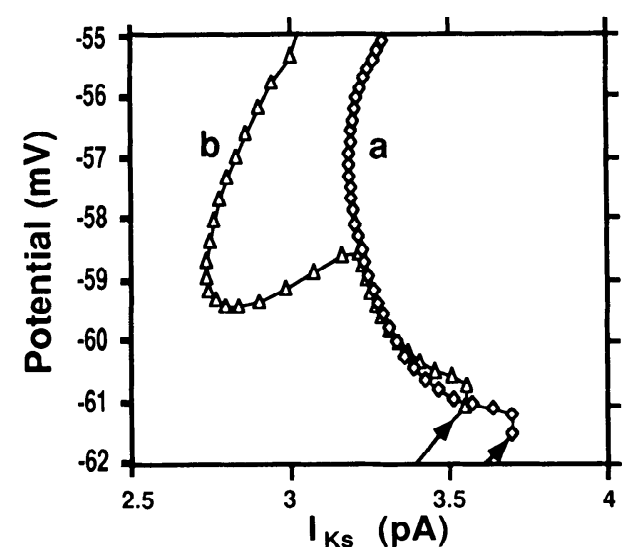

FIG. 12. Analysis of IPSP upward frequency entrainment in the 3-channel model. A: upper voltage trace shows a model cell being entrained by periodic IPSPs occurring at arrows. Boxed section labeled $\mathrm{a}$ and $\mathrm{b}$ are examined in phase planes below. $B$ : phase plane of voltage (ordinate) vs. total current (abscissa). Points on the traces are each separated by $0.4 \mathrm{~ms}$ so that the vertical distance between points indicates the rate of voltage change. This rate is proportional to total current because $C_{m} \dot{V}=I_{\text {total }}$. Trajectories enter from bottom left and exit at top. Effect of the IPSP in trace $b$ is seen as a loop of outward current off to the right. After the IPSP there is an increase in inward current, producing more rapid depolarization. This rapid depolarization reduces the interspike interval, increasing the firing rate. $C$ : phase plane of voltage (ordinate) vs. slow $\mathrm{K}^{+}$current (abscissa). Separation between points is $0.4 \mathrm{~ms}$. Net inward current that follows the IPSP is due to a decrease in outward current carried by $I_{\mathrm{K} s}$. Trajectories differ at the more depolarized voltages, where trajectory $b$ shows a large shift after the IPSP. This shift is due to the effect of the IPSP on the activation state ( $m$ variable) for this channel.
A

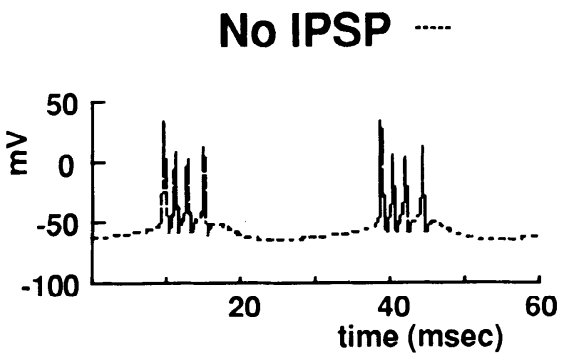

B

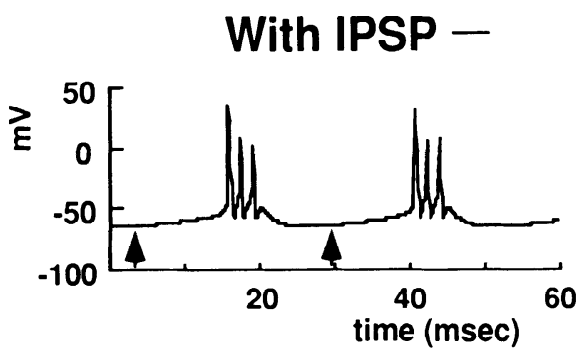

C

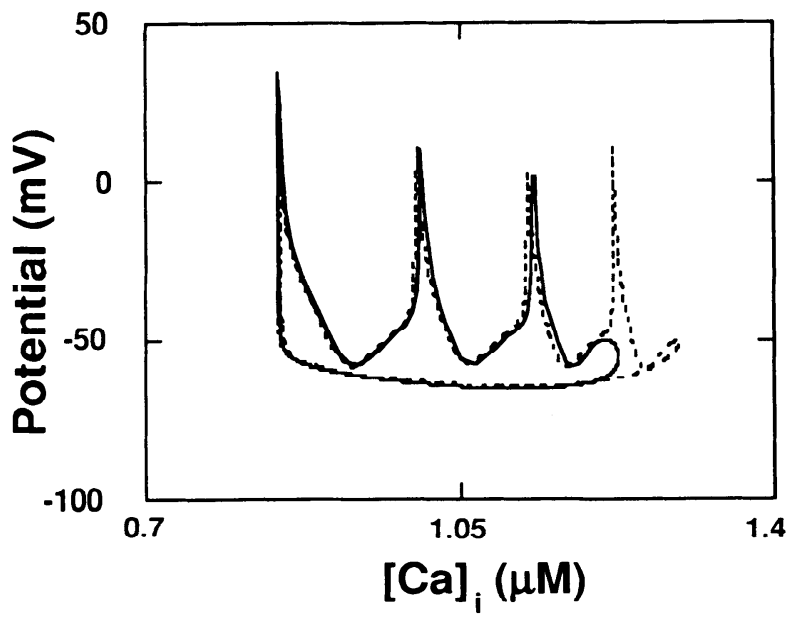

FIG. 13. The 11-channel model shows IPSP upward frequency entrainment due to the effect of the IPSPs on calcium entry. $A$ : membrane potential in the absence of IPSPs. Model shows 4spike bursts and a relatively long interburst interval. $B$ : membrane potential in the presence of IPSPs. Model shows 3-spike bursts and a shorter interburst interval. $C$ : phase plot of the membrane potential vs. calcium concentration in the submembrane shell. Difference in burst length produces different levels of internal calcium. Less calcium can enter with the 3-spike burst (-) than with the 4-spike burst (- - -). Decreased calcium level causes less activation of the calciumsensitive potassium channels. Reduced calciumsensitive potassium conductance permits a briefer interburst interval and faster frequency of bursting. 
A
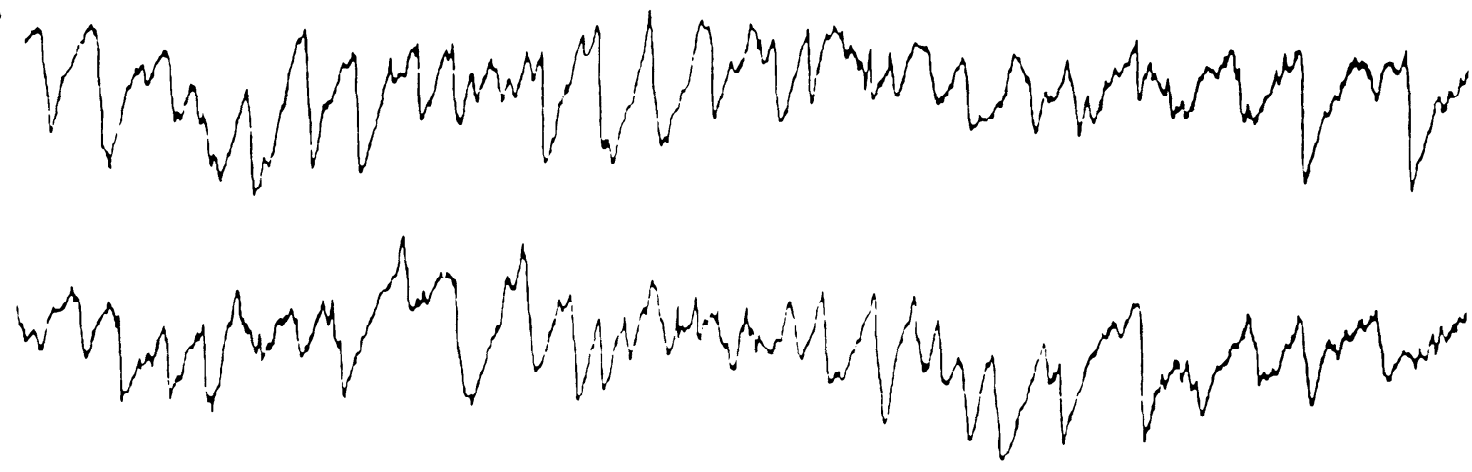

$5 \mathrm{mV}$

$100 \mathrm{~ms}$
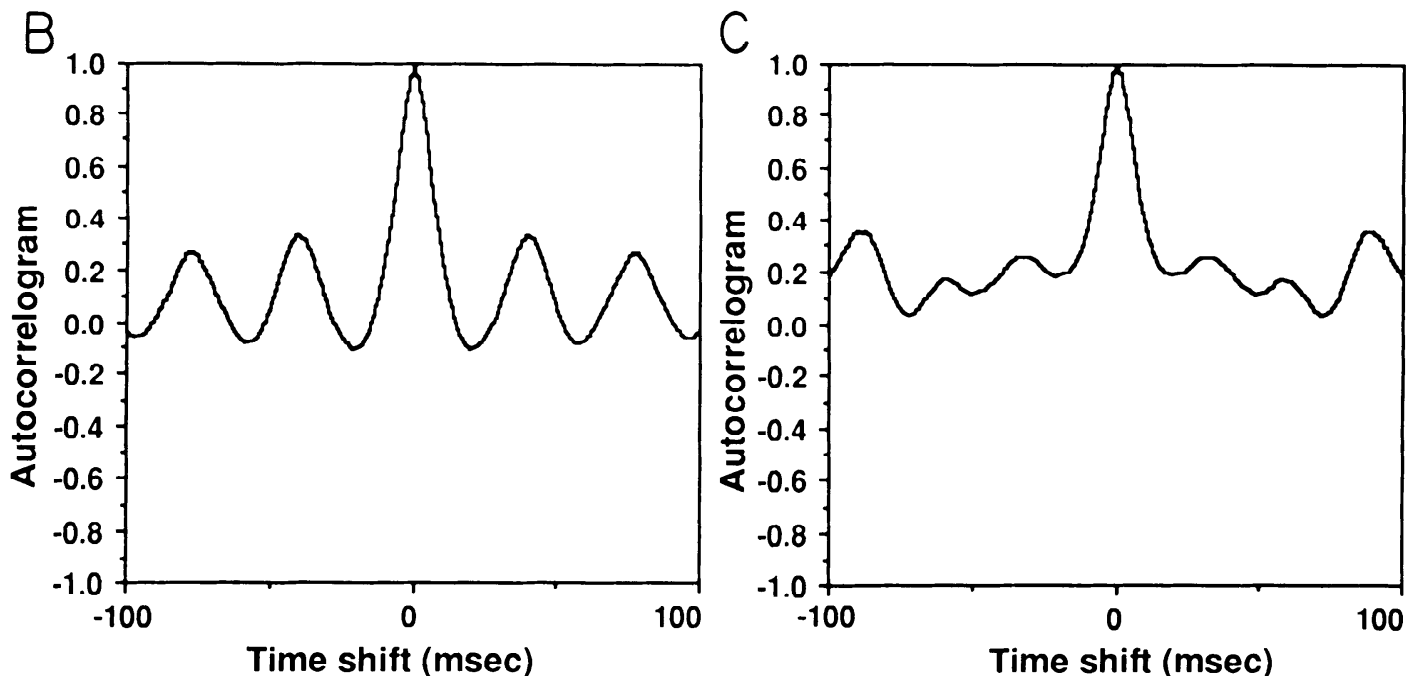

FIG. 14. Analysis of intracellular recordings from Fig. 11 of Ferster (1986) showing repetitive IPSPs. $A$ : recordings of membrane potential from a pyramidal cell in visual cortex of an anesthetized, paralyzed cat. Cell showed orientation sensitivity. Recording was made with an optimally oriented bar presented as a visual stimulus. IPSPs were isolated by depolarizing the cell with constant current injection to inactivate sodium channels and suppress spiking. Brief repetitive IPSPs of 5-10 mV were seen in both traces. Conductance change associated with these IPSPs cannot be calculated because the membrane potential was unknown. $B$ : autocorrelogram of $t o p$ trace in $A$. Peaks were seen at 40 and $80 \mathrm{~ms}$, corresponding to an underlying frequency of $25 \mathrm{~Hz}$. Note that both axes have different scales from previous correlograms. $C$ : autocorrelogram of bottom trace in $A$. Peaks were seen at 30,60 , and $90 \mathrm{~ms}$, corresponding to a frequency of $33 \mathrm{~Hz}$.

cells that project to the major thalamic nuclei (Steriade and Llinás 1988). The relay cells of these nuclei have a lowthreshold calcium channel that is deinactivated by hyperpolarization. The inhibitory neurons of the reticular nucleus may be involved in providing a rhythmic hyperpolarization that would entrain these cells through the anode break mechanism illustrated by our 3-channel model. This mechanism may also be important in absence epilepsy, a syndrome involving the thalamus that can be prevented with a pharmacological blocker of the low-threshold calcium channel ethosuximide (Coulter et al. 1989b; Pellegrini et al. 1989).

\section{Inhibition in cortical circuits}

It has often been assumed that "inhibitory contacts on the soma and on the initial segments are obviously most appropriately situated to prevent cells from firing" (Colon- nier 1981). This viewpoint ignores the graded nature of inhibition and the dynamic interplay between excitation and inhibition. Even when considering the traditional role of inhibition, it may be preferable to consider inhibition as delaying a cell's eventual firing rather than turning the cell off

There are many fewer inhibitory than excitatory synapses onto a pyramidal cell, but the synchronous firing of 40 inhibitory boutons on the soma may produce the same phase-locking seen with 4,000 excitatory boutons firing simultaneously in the dendrites. This 2-order-of-magnitude difference suggests that the inhibitory interneuron might be particularly important in phase-locking. It has been estimated that 15-20 basket cells converge onto one pyramidal cell perikaryon in neocortex, each of these providing four to five boutons (Martin 1984) Thus just six to eight cells, $40 \%$ of this total, could be sufficient to produce entrainment. Similarly, in hippocampus, the influence of a single inhibi- 
tory cell on a postsynaptic pyramidal cell is $5-9 \mathrm{nS}$, suggesting again that $5-10$ inhibitory cells could produce the requisite conductance to provide entrainment (Miles and Wong 1984). The limited range of axonal arborization of most inhibitory interneurons (generally $<1 \mathrm{~mm}$ ) could limit the spatial extent of this mechanism of synchronization to a single column. The use of inhibitory interneurons as the proximal cause of synchrony could permit widely separate columns to be synchronized without involving the columns that lie between them (Engel et al. 1990). Inhibitory interneurons would provide a relatively concentrated target for controlling synchrony in the column as a whole. The limited range of synchronization would also have the advantage of permitting a larger number of cells to be synchronized locally without risk of spread of synchronization producing a seizure.

Although repetitive firing could be caused by either the intrinsic membrane properties of individual neurons or by population effects due to periodic synaptic input, synchronization between neurons is necessarily dependent on synaptic interactions. The complex firing patterns seen in both pyramidal cells and interneurons subjected to currentclamp suggests that the intrinsic membrane properties of neurons probably contributes to repetitive firing. The membrane properties in our model neocortical neuron were critical in producing repetitive firing, and relatively weak synaptic input had significant effects on the timing of action potentials. Neurons that produce only a single burst in response to a current step might require strong periodic synaptic drive to elicit repetitive firing. Phase-locking would then demand far more synchrony of excitatory inputs than is required by our model.

We have presented a model of inhibitory effects in an isolated pyramidal cell. In cortex, these synaptic effects occur against a background of multiple excitatory and inhibitory interactions at a variety of time scales. Our study shows that inhibitory phase-locking will only occur in the setting of the appropriate amount of ongoing excitatory input. Far more complex interactions can be anticipated when the dynamics of multiple interconnected neurons are considered. The unexpected interplay of dynamic variables in our 11channel model is itself an illustration of the variety and richness of even a moderate-sized dynamical system.

We thank M. Hines for allowing us to use and to modify the CABLE neuron simulator; R. Douglas for providing us with the cortical cell morphology; and F. Crick, C. Koch, C. Gray, and P. Bush for many helpful discussions. The comments and suggestions of G. Shepherd and two anonymous referees were invaluable.

W. W. Lytton is supported by the National Institute of Aging through a Physician Scientist Award. T. J. Sejnowski was supported by the Drown Foundation and the Mather Foundation during the early part of this study and by the Howard Hughes Medical Institute during the later phases.

Address for reprint requests: W. Lytton, the Salk Institute, $10010 \mathrm{~N}$. Torrey Pines Rd., La Jolla, CA 92037.

Received 21 May 1990; accepted in final form 10 May 1991.

\section{REFERENCES}

Adams, P. R., Constanti, A., Brown, D. A., AND Clark, R. B. Intracellular $\mathrm{Ca}$ activates a fast voltage-sensitive $\mathrm{K}$ current in vertebrate sympathetic neurones. Nature Lond. 296: 746-749, 1982.

AGMON, A. AND CONNORS, B. W. Repetitive burst-firing neurons in the deep layers of mouse somatosensory cortex. Neurosci. Lett. 99: 137$141,1989$.

ANDERSEN, P. AND ANDERSSON, S. A. Physiological Basis of the Alpha Rhythm. New York: Appleton-Century-Crofts, 1968.

Bindman, L. J., MeYer, T., AND PRINCE, D. A. Comparison of the electrical properties of neocortical neurones in slices in vitro and in the anaesthetized rat. Exp. Brain Res. 69: 489-496, 1988.

BorG-GraHAM, L. J. Modeling the Somatic Electrical Response of Hippocampal Pyramidal Neurons (M.S. thesis). Cambridge, MA: MIT Press, 1987.

BORG-GrahAM, L. J. Modeling the non-linear conductances of excitable membranes. In: Cellular and Molecular Neurobiology: A Practical Approach, edited by H. Wheal and J. Chad. New York: Oxford Univ. Press, 1991.

Bryant, H. L., Marcos, A. R., ANd Segundo, J. P. Correlations of neuronal spike discharges produced by monosynaptic connections and by common inputs. J. Neurophysiol. 36: 205-225, 1973.

BUSH, P. AND DOUGLAS, R. J. Synchronization of bursting action potential discharge in a model network of neocortical neurons. Neural Computation 3: 19-30, 1991.

CARAFOLI, E. Intracellular calcium homeostasis. Annu. Rev. Biochem. 56: 395-443, 1987.

ChagnaC-Amitai, Y. ANd ConNors, B. W. Synchronized excitation and inhibition driven by intrinsically bursting neurons in neocortex. $J$. Neurophysiol. 62: 1149-1162, 1989.

ChagnaC-Amitai, Y., LuhmanN, H. J., ANd Prince, D. A. Burst generating and regular spiking layer 5 pyramidal neurons of rat neocortex have different morphological features. J. Comp. Neurol. 296: 598-613, 1990.

ChiU, S. Y., Mrose, H. E., AND Ritchie, J. M. Anomalous temperature dependence of the sodium conductance in rabbit nerve compared with frog nerve. Nature Lond. 279: 327-328, 1979.

COLONNIER, M. The electron-microscopic analysis of the neuronal organization of the cerebral cortex. In: The Organization of the Cerebral Cortex, edited by F. O. Schmitt, F. G. Worden, G. Adelman, and S. G. Dennis. Cambridge, MA: MIT Press, 1981, p. 125-153.

CONNORS, B. W. AND GUTNICK, M. J. Intrinsic firing patterns of diverse neocortical neurons. Trend Neurosci. 13: 99-104, 1990.

CONNORS, B. W., GUTNICK, M. J., AND PRINCE, D. A. Electrophysiological properties of neocortical neurons in vitro. J. Neurophysiol. 48: 13021320, 1982.

Connors, B. W., Malenka, R. C., and Silva, L. R. Two inhibitory postsynaptic potentials, and GABA-A and GABA-B receptor-mediated responses in neocortex of rat and cat. J. Physiol. Lond. 406: 443-468, 1988.

Constanti, A., Galvan, M., ANd Franz, P. Calcium-dependent inward currents in voltage-clamped guinea-pig olfactory cortex neurones. Eur. J. Physiol. 404: 259-265, 1985.

Coulter, D. A., Huguenard, J. R., And Prince, D. A. Calcium currents in rat thalamocortical relay neurones: kinetic properties of the transient low-threshold current. J. Physiol. Lond. 414: 587-604, 1989a.

COUlter, D. A., Huguenard, J. R., AND Prince, D. A. Characterization of ethosuximide reduction of low-threshold calcium current in thalamic neurons. Ann. Neurol. 25: 582-593, 1989b.

DAVENPORT, R., JAKOBSSON, E., AND GERGER, B. Possible dual effect of synapses that are putatively purely excitatory or purely inhibitory: bases in stability theory and implications for neural network behavior. Soc. Neurosci. Abstr. 516.9, 1989.

DAVIS, T. L. AND STERLING, P. Microcircuitry of cat visual cortex: classification of neurons in layer IV of area 17, and identification of the patterns of lateral geniculate output. J. Comp. Neurol. 188: 599-628, 1979.

Douglas, R. J. AND MaRTin, K. A. C. Control of neuronal output by inhibition at the axon initial segment. Neural Computation 2: 283-292, 1990a.

DouglaS, R. J. AND MaRTIN, K. A. C. Neocortex. In: The Synaptic Organization of the Brain, edited by G. M. Shepherd. New York: Oxford Univ. Press, 1990b, vol. 3, p. 389-438.

DUTAR, P. AND NICOLL, R. A. Pre- and postsynaptic GABA-B receptors in the hippocampus have different pharmacological properties. Neuron 1: 585-591, 1988.

ECKHORN, R., BAUER, R., Jordan, W., Brosch, M., Kruse, W., Munk, M., AND REITBOECK, H. J. Coherent oscillations: a mechanism of feature linking in the visual cortex. Biol. Cybern. 60: 121-130, 1988.

ECKhorn, R., Reitboeck, H. J., ARndT, M., AND Dicke, P. Feature 
linking via synchronization among distributed assemblies: simulations of results from cat visual cortex. Neural Computation 2: 293-307, 1990.

Edwards, F. A., Konnerth, A., Sakmann, B., and Takahashi, T. A thin slice preparation of patch clamp recordings from neurones of the mammalian central nervous system. Eur. J. Physiol. 414: 600-612, 1989

ENGel, A. K., Konig, P., Gray, C. M., ANd Singer, W. Stimulus-dependent neuronal oscillations in cat visual cortex: inter-columnar interaction as determined by cross-correlation analysis. Eur. J. Neurosci. 2: 588-606, 1990.

FERSTER, D. Orientation selectivity of synaptic potentials in neurons of cat primary visual cortex. J. Neurosci. 6: 1284-1301, 1986.

Fisher, R. E., GRay, R., AND Johnston, D. Properties and distribution of single voltage-gated calcium channels in adult hippocampal neurons, J. Neurophysiol. 64: 91-104, 1990.

Franz, P., Galvan, M., and Constanti, A. Calcium-dependent action potentials and associated inward currents in guinea-pig neocortical neurons in vitro. Brain Res. 366: 262-271, 1986.

FrenCH, C. R., SAH, P., Buckett, K. J., AND GaGe, P. W. A voltage-dependent persistent sodium current in mammalian hippocampal neurons. J. Gen. Physiol. 95: 1139-1157, 1990.

FRIEDMAN, A. AND GUTNICK, M. J. Low-threshold calcium electrogenesis in neocortical neurons. Neurosci. Lett. 81: 117-122, 1987.

Galvan, M., Constanti, A., Franz, P., Sedlmeir, C., and Endres, W. Calcium spikes and inward current in mammalian peripheral and central neurons. Exp. Brain Res. 14: 61-70, 1986.

Galvan, M., Franz, P., and Constanti, A. Spontaneous inhibitory postsynaptic potentials in guinea pig neocortex and olfactory cortex neurones. Neurosci. Lett. 57: 131-135, 1985.

Gray, C. M., ENGEL, A. K., Konig, P., ANDSINGer, W. Temporal properties of synchronous oscillatory neuronal interactions in cat striate cortex. In: Nonlinear Dynamics and Neural Networks, edited by H. G. Schuster and W. Singer. In press.

Gray, C. M., Konig, P., Engel, A. K., AND Singer, W. Oscillatory responses in cat visual cortex exhibit inter-columnar synchronization which reflects global stimulus properties. Nature Lond. 338: 334-337, 1989.

Gray, C. M. AND SINGER, W. Stimulus-specific neuronal oscillations in orientation columns of cat visual cortex. Proc. Natl. Acad. Sci. USA 86: 1698-1702, 1989.

Halliwell, J. V. M-current in human neocortical neurones. Neurosci. Lett. 67: 1-6, 1986

HALliwell, J. V. AND ADAMS, P. R. Voltage-clamp analysis of muscarinic excitation in hippocampal neurons. Brain Res. 250: 71-92, 1982.

Hartmann, H. A., Kirsch, G. E., Drewe, J. A., Taglialatela, M., JOHO, R. H., AND BROWN, A. M. Exchange of conduction pathways between two related K+ channels. Science Wash. DC 251: 942-944, 1991.

Hendry, S. H. C., Fuchs, J., DeBias, A. L., ANd Jones, E. G. Distribution and plasticity of immunocytochemically localized GABA-A receptors in adult monkey visual cortex. J. Neurosci. 10: 2438-2450, 1990.

HILlE, B. Ionic Channels of Excitable Membranes. Sunderland, MA: Sinauer, 1984.

HINES, M. L. A program for simulation of nerve equations with branching geometries. Int. J. Biomed. Comput. 24: 55-68, 1989.

HodGKIN, A. L. AND HuXLEY, A. F. A quantitative description of membrane current and its application of conduction and excitation in nerve. J. Physiol. Lond. 117: 500-544, 1952.

Huguenard, J. R., Hamill, O. P., AND Prince, D. A. Sodium channels in dendrites of rat cortical pyramidal neurons. Proc. Natl. Acad. Sci. USA 86: 2473-2477, 1989.

JaCk, J. J. B., Noble, D., AND Tsien, R. W. Electric Current Flow in Excitable Cells. New York: Oxford Univ. Press, 1983.

Kammen, D., Koch, C., And Holmes, P. J. Collective oscillations in the visual cortex. In: Neural Information Processing Systems 2, edited by D. S. Touretzky. San Mateo, CA: Morgan Kaufmann, 1990, p. 76-83.

KAY, A. R. AND WONG, R. K. S. Calcium current activation kinetics in isolated pyramidal neurones of the $\mathrm{CA} 1$ region of the mature guinea-pig hippócampus. J. Physiol. Lond. 392: 603-616, 1987.

Kimura, J., MiYamae, S., AND NOMA, A. Identification of sodium-calcium exchange current in single ventricular cells of guinea-pig. J. Physiol. Lond. 384: 199-222, 1987.

Kisvarday, Z. F., Martin, K. A. C., Friedlander, M. J., AND Somo-
GYI, P. Evidence for interlaminar inhibitory circuits in the striate cortex of the cat. J. Comp. Neurol. 260: 1-19, 1987.

КосH, C., DOUglas, R. J., AND WeHMEIER, U. Visibility of synaptically induced conductance changes: theory and simulations of anatomically characterized cortical pyramidal cells. J. Neurosci. 10: 1728-1744, 1990.

Konig, P. AND SCHILlen, T. B. Stimulus-dependent assembly formation of oscillatory responses: I. Synchronization. Neural Computation 3: 155-166, 1991a.

Konig, P. AND SCHILlEN, T. B. Stimulus-dependent assembly formation of oscillatory responses: II. Desynchronization. Neural Computation 3: $167-177,1991 \mathrm{~b}$

LANCASTER, B. AND ADAMS, P. R. Calcium-dependent current generating the afterhyperpolarization of hippocampal neurons. J. Neurophysiol. 55: $1268-1282,1986$.

Latorre, R., Oberhauser, A., Labarca, P., ANd Alvarez, O. Varieties of calcium-activated potassium channels. Annu. Rev. Physiol. 51: 385$399,1989$.

LLINÁS, R. AND GRACE, A. A. Intrinsic $40 \mathrm{~Hz}$ oscillatory properties of layer IV neurons in guinea pig cerebral cortex in vitro. Soc. Neurosci. Abstr. 268: 10, 1989.

LLINÁS, R., GRACE, A. A., AND YAROM, Y. In vitro neurons in mammalian cortical layer 4 exhibit intrinsic oscillatory activity in the 10- to 50-Hz frequency range. Proc. Natl. Acad. Sci. USA 88: 897-901, 1991. LLINÁs, R. AND MüHLETHALER, M. Electrophysiology of guinea-pig cerebellar nuclear cells in the in vitro brain stem-cerebellar preparation. $J$. Physiol. Lond. 404: 241-258, 1988.

LYTTON, W. W. Simulations of a phase comparing neuron of the electric fish Eigenmannia. J. Comp. Physiol. A Sens. Neural Behav. Physiol. In press.

Martin, K. A. C. Neuronal circuits in cat striate cortex. In: Cerebral Cortex, edited by E. G. Jones and A. Peters. New York: Plenum, 1984, p. 241-284.

Martin, K. A. C., Friedlander, M. J., AND Alones, V. J. Physiological, morphological and cytochemical characteristics of a layer 1 neuron in cat striate cortex. J. Clin. Neurophysiol. 282: 404-414, 1989.

MASON, A. AND LARKMAN, A. Correlations between morphology and electrophysiology of pyramidal neurons in slices of rat visual cortex. II. Electrophysiology, J. Neurosci. 10: 1415-1428, 1990.

MASON, A., Nicoll, A., AND StRatFoRd, K. Synaptic transmission between individual pyramidal neurons of the rat visual cortex in vitro. $J$. Neurosci. 11: 72-84, 1991

MCCORMICK, D. A. GABA as an inhibitory neurotransmitter in human cerebral cortex. J. Neurophysiol. 62: 1018-1027, 1989.

McCormick, D. A., ConNors, B. W., Lighthall, J. W., AND Prince, D. A. Comparative electrophysiology of pyramidal and sparsely spiny stellate neurons of the neocortex. J. Neurophysiol. 54: 782-806, 1985.

MCCORMICK, D. A. AND PRINCE, D. A. Two types of muscarinic response to acetylcholine in mammalian cortical neurons. Proc. Natl. Acad. Sci. USA 82: 6344-6348, 1985.

MILES, R. AND WoNG, R. K. S. Unitary inhibitory synaptic potentials in the guinea-pig hippocampus in vitro. J. Physiol. Lond. 356: 97-113, 1984.

MOCZYDLOWSKI, E. AND LATORRE, R. Gating kinetics of Ca-activated K channels from rat muscle incorporated into planar lipid bilayers. J. Gen. Physiol. 82: 511-542, 1983.

MOORE, J. W. AND HINES, M. L. Some consequences of intracellular calcium binding on phasic synaptic transmitter release. In: Calcium, Neuronal Function, and Transmitter Release. Boston, MA: Nijhoff, 1986, p. $115-140$.

MoOre, J. W., Hines, M. L., AND GobBle, J. K. HH channels alter summation of synaptic inputs in a model neuron. Soc. Neurosci. Abstr. 456.2, 1989.

Nowycky, M. C., Fox, A. P., AND TsIEN, R. W. Three type of neuronal calcium channel with different calcium agonist sensitivity. Nature Lond. 316: 440-443, 1985.

OgAwA, T., ITO, S., AND Kato, H. Membrane characteristics of visual cortical neurons in in vitro slices. Brain Res. 226: 315-319, 1981.

Pellegrini, A., Dossi, R. C., Dal Pos, F., ERmani, M., Zanotto, L., AND TeSTA, G. Ethosuximide alters intrathalamic and thalamocortical synchronizing mechanisms: a possible explanation of its antiabsence effect. Brain Res. 497: 344-360, 1989.

Pennefather, P., Sala, F., ANd Hernandez-Cruz, A. Computer simulation of IAHP kinetics. Soc. Neurosci. Abstr. 86: 10, 1990. 
Prince, D. A. AND Huguenard, J. R. Functional properties of neocortical neurons. In: Neurobiology of Neocortex, edited by P. Rakic and W. Singer. New York: Wiley, 1988, p. 153-176.

REGEHR, WS. G., CONNOR, J. A., AND TANK, D. W. Optical imaging of calcium accumulation in hippocampal pyramidal cells during synaptic activation. Nature Lond. 341: 533-536, 1989.

RUDY, B. Diversity and ubiquity of K channels. Neuroscience 25: 729_ 749, 1988.

RupPersberg, J. P., Schroter, K. H., SAKmanN, B., Stocker, M., SewING, S., AND PONGS, O. Heteromultimeric channels formed by rat brain potassium-channel proteins. Nature Lond. 345: 535-537, 1990.

SAH, P., GiBB, A. J., AND GaGE, P. W. The sodium current underlying action potential in guinea pig hippocampal CA1 neurons. J. Gen. Physiol. 91: 373-398, 1988.

Sala, F. and Hernandez-Cruz, A. Calcium diffusion modeling in a spherical neuron. Biophys. J. 57: 313-324, 1990.

SATO, H., DAW, N. W., AND Fox, K. Intracellular recording study of stimulus specific response properties in the cat visual cortcx. Soc. Neurosci. Abstr. 502.6, 1990.

SChARFMAN, H. E. AND SARVEY, J. M. Responses to GABA recorded from identified rat visual cortical neurons. Neuroscience 23: 407-422, 1987.

SCHWINDT, P. C., SPAIN, W. J., AND CRILL, W. E. Influence of anomalous rectifier activation on afterhyperpolarizations of neurons from cat sensorimotor cortex in vitro. J. Neurophysiol. 59: 468-481, 1988a.

SCHWINDT, P. C., SPAIN, W. J., AND CRILl, W. E. Long-lasting reduction of excitability by a sodium-dependent potassium current in cat neocortical neurons. J. Neurophysiol. 61: 233-244, 1989.

SCHWINDT, P. C., SPAIN, W. J., AND CRILl, W. E. Anomalous effects of intracellular calcium chelation in cat neocortical neurons. Soc. Neurosci. Abstr. 155: 1, 1990.

Schwindt, P. C., Spain, W. J., Foehring, R. C., Chubb, M. C., and CRILL, W. E. Slow conductance in neurons from cat sensorimotor cortex in vitro and their role in slow excitability changes. J. Neurophysiol. 59: 450-467, 1988b.

Schwindt, P. C., Spain, W. J., Foehring, R. C., Stafstrom, C. E., ChUBB, M. C., AND CRILL, W. E. Multiple potassium conductances and their functions in neurons from cat sensorimotor cortex in vitro. J. Neurophysiol. 59: 424-449, 1988c.

SEGAL, M. AND BARKER, J. L. Rat hippocampal neurons in culture: potassium conductances. J. Neurophysiol. 51: 1409-1433, 1984.

SEGAL, M. AND BARKER, J. L. Rat hippocampal neurons in culture: Ca and Ca-dependent K conductances. J. Neurophysiol. 55: 751-766, 1986.

SILVA, L. R., AMITAI, Y., AND CONNORS, B. W. Intrinsic oscillations of neocortex generated by layer 5 pyramidal neurons. Science Wash. DC 251: 432-435, 1991.

Somogyi, P., Nunzi, M. G., Gorio, A., AND Smith, A. D. A new type of specific interneuron in the monkey hippocampus forming synapses exclusively with the axon initial segments of pyramidal cells. Brain Res. 259: 137-142, 1983a.
SOMOGYI, P., SMITH, A. D., NunZI, M. G., GoRio, A., TAKAGI, H., AND WU, J. Y. Glutamate decarboxylase immunoreactivity in the hippocampus of the cat: distribution of immunoreactive synaptic terminals with special reference to the axon initial segment of pyramidal neurons. $J$. Neurosci. 3: 1450-1468, 1983b.

SpaIN, W. J., SCHWINDT, P. C., AND Crill, W. E. Anomalous Rectification in neurons from cat sensorimotor cortex in vitro. J. Neurophysiol. 57: 1555-1576, 1987.

Stafstrom, C. E., Schwindt, P. C., Chubb, M. C., AND Crill, W. E. Properties of persistent sodium conductance and calcium conductance of layer $\mathrm{V}$ neurons from cat sensorimotor cortex in vitro. J. Neurophysiol. 53: 153-170, 1985.

Stafstrom, C. E., Schwindt, P. C., ANd Crill, W. E. Negative slope conductance due to a persistent subthreshold sodium current in cat neocortical neurons in vitro. Brain Res. 236: 221-226, 1982

STERIADE, M. AND Llinás, R. The functional states of the thalamus and the associated neuronal interplay. Physiol. Rev. 68: 649-742, 1988.

STORM, J. F. Why is the input conductance of hippocampal neurones impaled with microelectrodes so much higher than when giga-seal patch pipettes are used? Soc. Neurosci. Abstr. 218: 4, 1990.

SUTOR, B. AND ZIEGLGÄNSBERGER, W. A low-voltage activated, transient calcium current is responsible for the time-dependent depolarizing inward rectification of rat neocortical neurons in vitro. Eur. J. Physiol. 410: 102-111, 1987.

Thompson, S. M., Deisz, R. A., AND Prince, D. A. Relative contributions of passive equilibrium and active transport to the distribution of chloride in mammalian cortical neurons. J. Neurophysiol. 60: 105-124, 1988.

TRAUB, R. Simulation of intrinsic bursting in CA3 hippocampal neurons. Neuroscience 7: 1233-1242, 1982.

WALTON, K. D., YaROM, Y., and Llinás, R. Intrinsic subthreshold 10$50 \mathrm{~Hz}$ membrane oscillations in interneurons in the fourth layer of the frontal cortex. Soc. Neurosci. Abstr. 54: 14-26, 1990.

WILSON, M. A. AND BOWER, J. M. The simulation of large-scale neural networks. In: Methods in Neuronal Modeling, edited by C. Koch and I. Segev. Cambridge, MA: MIT Press, 1989, p. 291-334.

WOLFSON, B., GUTNICK, M. J., AND BALDINO, F. Electrophysiological characteristics of neurons in neocortical explant cultures. Exp. Brain Res. 76: 122-130, 1989.

WOODY, C. D. AND GRUEN, E. Characterization of electrophysiological properties of intracellularly recorded neurons in the neocortex of awake cats: a comparison of the response to injected current in spike overshoot and undershoot neurons. Brain Res. 158: 343-357, 1978.

ZONA, C. AND Avoli, M. Calcium-activated potassium channels recorded from rat neocortical neurons in cell culture. Neurosci. Lett. 102: 223228, 1989.

Zona, C., Pirrone, G., Avoli, M., AND Dichter, M. Delayed and fast transient potassium currents in rat neocortical neurons in cell culture. Neurosci. Lett. 94: 285-290, 1988. 